\title{
Unraveling Photocatalytic Mechanism and Selectivity in PET-RAFT Polymerization
}

\section{Seal, Prasenjit}

2019-06

Seal , P , Xu , J , De Luca , S , Boyer , C \& Smith , S C 2019 , ' Unraveling Photocatalytic Mechanism and Selectivity in PET-RAFT Polymerization ' , Advanced theory and simulations , vol. 2 , no. 6 , 1900038 . https://doi.org/10.1002/adts.201900038

http://hdl.handle.net/10138/315714

https://doi.org/10.1002/adts.201900038

unspecified

acceptedVersion

Downloaded from Helda, University of Helsinki institutional repository.

This is an electronic reprint of the original article.

This reprint may differ from the original in pagination and typographic detail.

Please cite the original version. 


\title{
Unravelling Photocatalytic Mechanism and Selectivity in PET-RAFT Polymerization
}

Prasenjit Seal, * Jiangtao Xu, Sergio De Luca, Cyrille Boyer, and Sean C. Smith*

\author{
Dr. P. Seal \\ Department of Chemistry, University of Helsinki, P.O. Box 55 (A.I. Virtasen aukio 1), \\ Helsinki 00014, Finland \\ E-mail: prasenjit.seal@helsinki.fi \\ This work was performed while pursuing postdoctoral work at UNSW, Australia \\ Dr. J. Xu, Prof. C. Boyer \\ Centre for Advanced Macromolecular Design (CAMD) and Australian Centre for \\ NanoMedicine, School of Chemical Engineering, UNSW Australia, Sydney, New South \\ Wales 2052, Australia \\ Dr. S. D. Luca \\ Integrated Materials Design Centre (IMDC), School of Chemical Engineering, UNSW \\ Australia, NSW 2052, Sydney, Australia \\ Prof. S. C. Smith \\ Department of Applied Mathematics, Research School of Physics and Engineering, The \\ Australian National University, ACT 2601, Acton, Australia \\ E-mail: sean.smith@anu.edu.au
}

Keywords: catalyst selectivity, molecular orbital analyses, photoinduced electron/energy transfer reversible addition-fragmentation chain transfer, pheophorbide $a$, reversible additionfragmentation chain transfer agents

The photoredox catalysts pheophorbide $a$ (PheoA) and zinc tetraphenylporphine (ZnTPP) under illumination display strong selectivity towards reversible addition-fragmentation chain transfer (RAFT) agents containing thiocarbonylthio groups, namely dithiobenzoates, xanthates and trithiocarbonates. The underlying mechanism for the process - whether via energy or electron transfer from the photoexcited catalyst to RAFT agent has remained unclear, as has the reason for the remarkable selectivity. Quantum chemistry and molecular dynamics calculations are utilized to provide strong evidence that none of the common energy transfer mechanisms (Förster resonance energy transfer; Dexter electron exchange; or internal conversion followed by vibrational energy transfer) is likely to facilitate polymerisation, let alone explain the observed selectivities. In contrast, extensive quantum chemical characterizations of the excited state orbitals associated with the catalyst-RAFT agent 


\section{WILEY-VCH}

complexes uncover a clear selectivity pattern associated with charge transfer states that is highly consistent with experimental findings. The results shed light on the intrinsic catalytic role of the photocatalysts and provide a strong indication that a reversible electron/charge transfer mechanism underpins the remarkable photocatalytic selectivity.

\section{Introduction}

The sustainability of life hinges critically on natural photosynthesis, where nature converts solar energy to chemical energy in plants. This is usually done through complex photoredox and energy transfer processes and has offered a profound challenge to researchers ${ }^{[1-3]}$ who tried to model this natural phenomenon. In 1912, Ciamician ${ }^{[1]}$ inspired by this phenomenon, used visible light to mediate chemical reactions using photochemistry. Over the subsequent century, interest has grown in finding new systems that are capable of absorbing light and mediating chemical reactions for the production of fine chemicals and advanced materials. The use of photoredox catalysts in particular has been the subject of intense interest in recent years for the purpose of initiating polymerization reactions with high efficiency and minimal by-product formation. ${ }^{[4-11]}$

As the name suggests, these photoredox catalysts harnesses the energy of visible light to accelerate a chemical reaction through electron-transfer processes. A number of such catalysts exhibit exceptional compatibility and selectivity. ${ }^{[12]}$ The property of compatibility has led to some recent developments in the field of visible-light photocatalysis, where different catalysts are utilized to perform complex organic reactions in single pot. ${ }^{[13]}$ Besides the compatibility factor, selectivity of the photoredox catalysts to activate specific substrates or specific groups in a system is an important feature ${ }^{[14]}$ Utilization of photoredox catalysts in polymer chemistry has led to novel light-mediated polymerization schemes, demonstrating that the approach enables spatial and temporal control that is a powerful tool for material fabrication and chemical transformation. ${ }^{[5,14-23]}$ Inspired by this, Boyer and co-workers have 


\section{WILEY-VCH}

recently utilized photoredox catalysts, ${ }^{[4,8,17,18]}$ such as pheophorbide $a$ (PheoA) and zinc tetraphenylporphine (ZnTPP), to mediate photoinduced electron/energy transfer reversible addition-fragmentation chain transfer (PET-RAFT) polymerization (Scheme 1).

The versatility and effectiveness of this PET-RAFT technique has been demonstrated in different media with the use of a range of wavelengths in the visible region. ${ }^{[16,24-28]}$ As specific examples, considering the activity of PheoA (Figure 1a) and ZnTPP (Figure 1b) with respect to a set of six RAFT agents which comprise dithiobenzoates (4-cyanopentanoic acid dithiobenzoate: CPADB, 2-cyano-2-propyl benzodithioate: CPD, cumyl dithiobenzoate: CDB), xanthate (2-[(ethoxycarbonothioyl)sulfanyl] propanoate: Xanthate), and trithiocarbonate (3-benzylsulfanyl-thiocarbonylthiosulfanyl propionic acid: BSTP, 2-(nbutyltrithiocarbonate)-propionic acid: BTPA) moieties, the details of which are given specifically in Figure 1c-h, PheoA displays exceptional catalytic selectivity towards CPADB compared to either xanthates or trithiocarbonates; ${ }^{[4]}$ whereas ZnTPP selectively activates the trithiocarbonates for the polymerization of methacrylates, styrenes, etc. ${ }^{[17,29,30]}$

Two important mechanistic questions are thrown up by these developments: (i) Ought the "ET" in PET-RAFT to stand for electron transfer (Scheme 1A) or energy transfer (Scheme 1B)? The acronym is tacitly ambiguous in the absence of evidence to suggest one or the other. (ii) What is the origin of the selectivity of the mentioned photoredox catalysts for specific RAFT agents? In this work, our objective has been to provide theoretical evidence towards the resolution of these questions. Addressing question (i), we explore and subsequently discount three distinct scenarios of energy transfer between photocatalyst and RAFT agent: Förster resonance energy transfer; ${ }^{[31]}$ Dexter electron exchange; ${ }^{[32]}$ and internal conversion followed by vibrational energy transfer. This part of our study negates the likelihood that energy transfer can initiate the polymerisation and provides a clear indication that electron transfer, yielding a charge transfer state within the photocatalyst-RAFT agent complex, is likely to be the operational mechanism for the systems studied. Addressing question (ii), we 


\section{WILEY-VCH}

implement extensive quantum chemical characterisations of the molecular orbital manifolds associated with the first excited electronic state of the respective complexes between the catalysts and the RAFT agents. Straightforward analysis of the energetic proximity of electron transfer states to the initial optical excitation state suggests a simple rationale for explaining the experimentally observed selectivities.

\section{Results and Discussion}

It has been observed that a variety of photoredox catalysts such as transition metal complexes, organic dyes, metalloporphyrins, and naturally derived catalysts like chlorophyll can mediate PET-RAFT polymerization process. ${ }^{[17,33]}$ The $M 05^{[34]} 6-31 \mathrm{G}(\mathrm{d})+\mathrm{D} 3^{[35]}$ optimized geometries of the catalysts and RAFT agents studied are presented in Figure 1. PheoA (Figure 1a), is an organic porphyrin originating from the chlorophyll breakdown, ${ }^{[4]}$ and ZnTPP (Figure 1b), is a metalloporphyrin. The six RAFT agents can be divided into three categories. Figure 1c-e are the dithiobenzoates, CPADB, $\mathrm{CPD}$, and $\mathrm{CDB}$, where the $-\mathrm{C}(=\mathrm{S}) \mathrm{S}-$ group is connected with the benzene ring. There is one xanthate RAFT agent with the general formula of R-O$\mathrm{C}(=\mathrm{S}) \mathrm{S}-\mathrm{R}^{\prime}$ as given in Figure 1f. The other two RAFT agents shown in Figure 1g (BSTP) and Figure $1 \mathrm{~h}(\mathrm{BTPA})$ are from the trithiocarbonate family with the $-\mathrm{SC}(=\mathrm{S}) \mathrm{S}-$ group. Note for later reference that the dithiobenzoates, CPADB, CPD and CDB differ only in the tail group or "R group" - on the right-hand end of the structures in Figure 1c-e. For clarity, we presented the chemical drawings of the systems under consideration in Figure S1 in the Supporting Information. We utilize nomenclature for all the molecules and the complexes as presented in Table S1 in the Supporting Information.

We also calculated the stabilities of the RAFT agents with respect to fragmentation either (i) in the anionic state consistent with Scheme 1A or (ii) in the ground electronic state consistent with Scheme 1B. In all cases the anionic RAFT agents were found to be unstable with respect to fragmentation. The ground state fragmentation barriers for the two RAFT 


\section{WILEY-VCH}

agents studied in the MD simulations, CPADB and BTPA, were calculated to be 37.9 and $51.5 \mathrm{kcal} \mathrm{mol}^{-1}$ respectively (see also Table 1; Figure 2a,b lower frames). The energy analysis as described were performed at M05/6-31G(d)+D3 level of theory using DMSO as solvent to mimic the experimental condition. We estimated the binding energies of CPADB and BTPA w.r.t. their fragmentation. For both the schemes, it is the difference between the energies of the constituents after fragmentation and the original species.

We begin with a consideration of the first mechanistic question posed above, namely whether energy transfer (Scheme 1B) or electron transfer (Scheme 1A) is the operational mechanism. There are three distinct energy transfer mechanisms that could potentially mediate the RAFT agent activation for subsequent polymerisation: (i) Förster resonant energy transfer from photocatalyst to RAFT agent. In this case, the photocatalyst drops from its $\mathrm{S}_{1}$ to its $\mathrm{S}_{0}$ state as dipole-dipole coupling allows the RAFT agent to become excited into its $\mathrm{S}_{1}$ state, potentially leading to fragmentation and polymerisation. (ii) Dexter electron exchange between photocatalyst and RAFT agent. Here, the excited electron from the photocatalyst in its $\mathrm{S}_{1}$ state undergoes intracomplex transfer into an excited orbital of the RAFT agent; while at the same time an electron from the HOMO orbital of the RAFT agent undergoes reverse intracomplex transfer to the HOMO orbital of the catalyst. The net result is the same as for the Förster mechanism: the RAFT agent ends up in its $\mathrm{S}_{1}$ state while the photocatalyst ends up in its ground state. (iii) Internal conversion (IC) of the photocatalyst from $\mathrm{S}_{1}$ to $\mathrm{S}_{0}$, or intersystem crossing (ISC) from $\mathrm{T}_{1}$ to $\mathrm{S}_{0}$, yields a highly vibrationally excited catalyst molecule in its ground electronic state. Subsequent vibrational energy transfer from the highly excited catalyst to an adjacent RAFT agent may then cause fragmentation of the RAFT agent, followed by propagation and recombination as sketched in Scheme 1B.

As noted above, the net result of the Förster energy transfer mechanism (i) and the Dexter electron exchange mechanism (ii) is the same: the photocatalyst drops to its ground electronic state $\mathrm{S}_{0}$, while the RAFT agent is lifted into its (neutral) $\mathrm{S}_{1}$ state. Thus, 


\section{WILEY-VCH}

investigation of the likelihood of either of these mechanisms should focus on whether the $\mathrm{S}_{1}$

state of the RAFT agents can undergo fragmentation and thereby lead to polymerisation. Table 1 provides the calculated barriers for fragmentation of the RAFT agents in this study both in their ground $\left(\mathrm{S}_{0}\right)$ electronic states and in their first excited $\left(\mathrm{S}_{1}\right)$ electronic states. One immediately identifies that the RAFT agents are all strongly bound in their $\mathrm{S}_{1}$ states, such that - irrespective of whether via Förster or Dexter mechanisms - they will not be activated in the $\mathrm{S}_{1}$ state. Another potential mechanism might be that the RAFT agents could undergo internal conversion to yield highly vibrationally excited ground state RAFT agents, which might undergo fragmentation leading to subsequent polymerisation. However, as is apparent in Table 1 , the $\mathrm{S}_{0}-\mathrm{S}_{1}$ energy gap that would be released as vibrational energy in the RAFT agents is barely enough to cause fragmentation of the RAFT agents in their ground electronic $\left(\mathrm{S}_{0}\right)$ state. Given that such fragmentation is competing with collisional quenching of the vibrational energy by the surrounding solvent, the likelihood that this mechanism operates is very small.

The third energy transfer mechanism involves internal conversion (IC) of the photocatalyst from $S_{1}$ to $S_{0}$, or intersystem crossing (ISC) from $T_{1}$ to $S_{0}$, yielding a highly vibrationally excited catalyst molecule in its ground electronic state. Subsequent vibrational energy transfer from the catalyst to an adjacent RAFT agent may then cause fragmentation of the RAFT agent, followed by propagation and recombination as sketched in Scheme 1B. While such bond fissions are well known in the context of photoactivated unimolecular dissociation reactions, the mechanism requires that there is rapid vibrational coupling to facilitate fragmentation of the labile bond before the excitation energy is quenched by collisions with the surrounding solvent molecules. In the present case, one may question whether the coupling from catalyst to RAFT agent is sufficiently rapid, given that the two are not linked by chemical bonds but rather relatively weak van der Waals bonds. To gain insight into this mechanistic pathway, we performed MD simulations for the PheoA-CPADB and 


\section{WILEY-VCH}

PheoA-BTPA complexes as representative examples, the former known experimentally to be favourable while the latter does not lead to reaction at all. ${ }^{[4]}$ The initial conditions are set up so as to mimic the highly vibrationally excited photocatalyst (i.e., after transition from the excited electronic state to the ground state) in an ambient-temperature bath consisting of one adjacent RAFT agent and several solvent molecules. This is achieved as described above by selectively imparting an elevated temperature to the catalyst via independent thermostatting in the initial simulation - the elevated temperature being chosen such that the average vibrational energy of the photocatalyst is equivalent to the calculated optical excitation energy. We examine whether sufficient vibrational excitation is transferred to the RAFT agent to enable its fragmentation before quenching from solvent collisions occurs. Figure 2a presents the variations of temperature with time for PheoA-CPADB complex in DMSO medium. The time at which we switch to NVE simulation - allowing the photocatalyst, RAFT agent and solvent molecules to dynamically exchange energy without any thermostat forcing - is highlighted in the figure with a blue vertical dashed line. As expected, the figure reveals that the temperature of the catalyst decreases in time as those of the RAFT agent and solvent molecules increase. We also calculate the average vibrational thermal energies at regular $5 \mathrm{ps}$ intervals and plot these for the PheoA catalyst and the CPADB RAFT agent in the lower frame over the period $250-350 \mathrm{ps.} \mathrm{In} \mathrm{the} \mathrm{energy} \mathrm{plot,} \mathrm{the} \mathrm{green} \mathrm{horizontal} \mathrm{dashed} \mathrm{line} \mathrm{is} \mathrm{the}$ energy (calculated as described above) needed to cleave the RAFT agent to form the requisite radical in the ground electronic state, thereby propagating the reaction sequence as presented in Scheme 1B. In Figure 2b, we plot similar data for the PheoA-BTPA complex for comparison. For both simulations, the upper-frame temperature plots reveal that energy from the catalyst dissipates democratically out into nearby solvent molecules and the RAFT agent. It is clear from the lower-frame plots of average vibrational energies that the RAFT agents at no point come anywhere close to acquiring sufficient energy to fragment into radicals in their ground electronic states. Neither is there any apparent difference in the dynamics of energy 


\section{WILEY-VCH}

transfer that would bear out the selective activation of CPADB over BTPA by the PheoA photocatalyst.

On the basis of these simulations, we rule out energy transfer mechanisms (i) - (iii) above and proceed to seek a mechanistic explanation for the remarkable selectivity of the photocatalysts towards certain RAFT agents in the context of the electron-transfer mechanism, Scheme 1A. Thus, the more precise descriptor "photoredox catalyst" is indeed appropriate.

The electron transfer mechanistic pathway of Scheme 1A merits some elaboration. It begins with the activation of the photocatalyst by a certain wavelength of light from the $S_{0}$ to the $S_{1}$ electronic state. Unless the catalyst is already pre-complexed with a RAFT agent and can undergo intracomplex electron transfer and activation directly from the $\mathrm{S}_{1}$ state (more on this below); it may undergo ISC to the triplet state $T_{1}$. The $T_{1}$ state has a longer lifetime, increasing the chances to subsequently encounter and complex with a RAFT agent. Once the complex is formed, the catalyst can potentially transfer an electron to the RAFT agent to initiate the RAFT process (Scheme 1A), forming the cationic catalyst and anionic RAFT agent. It is important at this point to re-emphasize the results concerning stability of the anionic RAFT agents noted above: namely that in all cases they are found to be unstable with respect to dissociation into radical and anion components. Hence, the RAFT agent then decomposes directly to produce a monomeric or polymeric radical and a residual complex of the cationic catalyst and the Z-C(=S)-S anion ${ }^{[36]}$ as shown in Scheme 1A. Subsequently, the radical either propagates with monomers or it can transfer with other RAFT agents. These radicals can then be deactivated by the residual charge-transfer complex mentioned above to regenerate a now-extended RAFT agent complexed with the ground state photoredox catalyst. It is noteworthy to mention at this point that - if the binding energy of the catalyst-RAFTagent complex is sufficient, the complex may persist until the next photoexcitation event. In such case, the subsequent photoredox mechanism would proceed direct from the $\mathrm{S}_{1}$ state 


\section{WILEY-VCH}

rather than the $T_{1}$ state, since the immediate proximity of the RAFT agent will facilitate direct electron transfer from $\mathrm{S}_{1}$ before ISC occurs.

The binding energy of the PheoA catalyst for complexation with each of the six RAFT agents studied was calculated initially in order to examine whether its selectivity for activation of the CPADB RAFT agent might simply correlate to preferential complexation, which could facilitate the electron transfer. The results, presented in Table S2 in the Supporting Information, indicate complex binding energies are typically in the range 20-30 kcal $\mathrm{mol}^{-1}$ and that the PheoA-CPADB complex does not stand out in any obvious way. This result should not be very surprising given that - also apparent in Table S2 in the Supporting Information - dispersion energies associated with the van der Waals interactions are a major contributor to the binding energies and are generally quite non-specific. Thus, our investigation zeros in on the excited state electron transfer step for each of these complexes in order to seek the explanation for the selectivity.

It is relevant to compare the complexation energy between the catalyst and the RAFT agent with that between the catalyst and a DMSO solvent molecule, with a view to understanding the likelihood that the catalyst - RAFT agent complex will be persistent over significant periods of time. Using the PheoA catalyst and the CPADB RAFT agent as examples, the complexation energy for the PheoA-CPADB interaction, calculated for an implicit DMSO solvent environment, is found to be $-24.5 \mathrm{kcal} \mathrm{mol}^{-1}$. The complexation energy for the PheoA-DMSO interaction, again calculated for an implicit DMSO solvent environment, is found to be $-11.3 \mathrm{kcal} \mathrm{mol}^{-1}$. Going a step further to consider the RAFT agent with one MMA monomer inserted (CP-MMA-DB), the complexation energy for the PheoA(CP-MMA-DB) interaction with implicit DMSO solvent is calculated to be $-27.6 \mathrm{kcal} \mathrm{mol}^{-1}$. These results do indeed suggest that the catalyst - RAFT agent complex is likely to be a persistent one, such that most catalysts in solution will likely be pre-complexed when the optical excitation occurs. Recapping on the discussion above, this implies that excited state 


\section{WILEY-VCH}

electron transfer should occur directly from the $S_{1}$ excited state that is accessed by the optical excitation. From the point of view of examining the propensities for excited state electron transfer across the range of six studied RAFT agents, this is somewhat adventitious, since as noted above we have found that convergence of the $T_{1}$ excited state complex energies was much more challenging than for the $\mathrm{S}_{1}$ excited state complex. Furthermore, as is shown in detail below, there is a remarkable consistency between the experimentally determined selectivity and that predicted theoretically based on analysis of the $\mathrm{S}_{1}$ excited state complexes.

Before going into a detailed discussion of these analyses, it is useful to look at the structure of the catalyst, PheoA. This photocatalyst is asymmetric with two distinct faces, as is clear from Figure S2 in the Supporting Information. Face 1 (F1) has the $-\mathrm{COOH}$ group present while face $2(\mathrm{~F} 2)$ has the presence of methyl ester $\left(-\mathrm{COOCH}_{3}\right)$ group. We explored the possibility of interactions of PheoA with all the RAFT agents at both these surfaces. We started by calculating the energetics of the ground-state optimized structures for the PheoARAFT agent complexes. Detailed results are tabulated for the M05/6-31G(d) and vdW corrected energies in Table S2 in the Supporting Information. We take into account both the surfaces of PheoA and also include DMSO as an implicit solvent. From Table S2 in the Supporting Information, it is quite clear that the difference in energy values between the complexes $\left(E_{\mathrm{DFT}+\mathrm{D} 3}^{\mathrm{F} 1}-E_{\mathrm{DFT}+\mathrm{D} 3}^{\mathrm{F} 2}\right)$ at both the faces $\mathrm{F} 1$ and $\mathrm{F} 2$ are small; hence we have used only one surface, i.e., F1, for subsequent analyses. For the optimizations with an implicit DMSO solvent environment, we observed that the trends obtained in the energy values are similar to the gas-phase. Inspection of the values tabulated in Table S2 in the Supporting Information clearly reveals that non-covalent interactions play a very important role in these complexes, with energy contributions as high as $-52.7 \mathrm{kcal} \mathrm{mol}^{-1}$ to the ground state energies. Hence, we continued with the DFT + D3 method for all of the subsequent excited state calculations. The dispersion-corrected binding energies for the PheoA-RAFT complexes were also tabulated in Table S2 in the Supporting Information and the values are obtained from the 


\section{WILEY-VCH}

energy differences between the complex and the separated entities. The relevant formula is given in the footnote of the table. As noted above, these binding energies indeed indicate that the complex formation is favourable and persistent in these systems.

We now turn to the molecular orbital analyses of the catalyst-RAFT agent complexes optimized for the first excited singlet state $\mathrm{S}_{1}$. Figure $\mathrm{S} 3$ in the Supporting Information shows the top and side views of the excited-state optimized structures for four representative catalyst-RAFT agent complexes, $\mathrm{PC}_{1}(\mathrm{~F} 1)-\mathrm{RA}_{1}, \mathrm{PC}_{1}(\mathrm{~F} 1)-\mathrm{RA}_{6}, \mathrm{PC}_{2}-\mathrm{RA}_{1}$ and $\mathrm{PC}_{2}-\mathrm{RA}_{6}$. All are found to have stacked geometry similar to the ground state complexes. We extracted the relevant manifold of orbitals, i.e., highest occupied molecular orbital (HOMO) and the three lowest unoccupied molecular orbitals (LUMO, LUMO+1, and LUMO+2) from the corresponding checkpoint files obtained from Gaussian $09^{[37]}$ excited-state TDDFT calculations. Figure 3 presents two representative pairs of lowest energy LUMO $+x$ orbitals obtained at M05/6-31G(d)+D3 level of theory having electron density predominantly (i) on the catalyst and then contrastingly (ii) on the RAFT agent. We take the former to represent the most likely orbital that will be populated upon initial optical excitation and the latter to be the nearest-lying charge-transfer state that could mediate donation of the excited electron to the RAFT agent. Corresponding orbital plots for all of the other catalyst-RAFT combinations are shown in Figure S4 in the Supporting Information. Analyses of the Figure 3 and Figure S4 in the Supporting Information illustrates that for the PheoA-dithiobenzoate complexes, $\mathrm{PC}_{1}-\mathrm{RA}_{1}$ and $\mathrm{PC}_{1}-\mathrm{RA}_{3}$, it is the LUMO+1 where we found the primary contributions from the RAFT agents while for the $\mathrm{PC}_{1}-\mathrm{RA}_{2}$ complex, it is the LUMO orbital which has the major part coming from the RAFT agent, CPD. In case of PheoA-xanthate $\left(\mathrm{PC}_{1}-\mathrm{RA}_{4}\right)$ and PheoAtrithiocarbonate $\left(\mathrm{PC}_{1}-\mathrm{RA}_{5}\right.$ and $\left.\mathrm{PC}_{1}-\mathrm{RA}_{6}\right)$ complexes, it is the $\mathrm{LUMO}+2$, which has a prevailing RAFT agent contributions. The M05/6-31G(d)+D3 molecular orbitals which are less likely to be involved in mediating the electron transfer are also plotted in Figure S4 in the Supporting Information. Those are the HOMO and $\mathrm{LUMO}+2$ for the catalyst-dithiobenzoate 


\section{WILEY-VCH}

complexes and $\mathrm{HOMO}$ and $\mathrm{LUMO}+1$ for catalyst-xanthate and catalyst-trithiocarbonate complexes. In all these cases, the dominant contributions are from the catalysts, PheoA and ZnTPP only. Note that in the case of the ZnTPP catalyst, in fact the two lowest lying LUMO states with density residing predominantly on the catalyst are close in energy. While in principle both such orbitals could be actively involved in mediating the optical excitation and charge transfer, the simple theoretical rationale we derive in this work will not alter from the choice of just the lower energy orbital. For reference, the HOMO and LUMO plots for the catalyst and independently for the RAFT agents are also shown in Figure S5 in the Supporting Information.

Table 2 provides a detailed excited-state molecular orbital analysis in gas-phase where we tabulated all the relevant singlet-state molecular orbital energy values obtained both from M05/6-31G(d)+D3 and B3LYP ${ }^{[38,39] / 6-31 G(d)+D 3 ~ l e v e l ~ o f ~ t h e o r y . ~ W e ~ a l s o ~ p r e s e n t e d ~ t h e ~}$ excited triplet-state for the three PheoA-dithiobenzoate complexes and solvent (DMSO)-phase results for all the six PheoA-RAFT complexes in Table S3 and Table S4 in the Supporting Information, respectively. In each of these tables, we highlighted the lowest lying chargetransfer LUMO state in red colour. The last two columns, i.e., crucial transition energy gap and whether that crucial transition is uphill(U)/downhill(D) in energy are quite interesting and present features that may play an important role. The crucial transition here is obtained by taking the energy difference between the charge-transfer state and the first optical excitation state (i.e., with oscillator strength driven by the electron density being predominantly on the catalyst). As an example, taking the case of $\mathrm{PC}_{1}-\mathrm{RA}_{1}$, we have the LUMO as the first allowed optically excited state with the charge-transfer state being LUMO+1. Hence, the crucial transition $(\mathrm{CT})$ energy gap $=E_{\mathrm{LUMO}+1}-E_{\mathrm{LUMO}}$. The same notion goes for the other complexes at the level of theories studied. Since this electron-transfer transition is energetically uphill in an energy diagram, we denoted that as $\mathrm{U}$ in the final column of Table 2. For the $\mathrm{PC}_{1}-\mathrm{RA}_{2}$ complex, although we have the CT energy gap as $E_{\mathrm{LUMO}+1}-E_{\mathrm{LUMO}}$, yet it is energetically 


\section{WILEY-VCH}

downhill (D) since the electron first gets optically excited to LUMO+1 followed by a chargetransfer to LUMO. Table 2 also shows differences in the orbital energy values obtained using M05 and B3LYP functionals. The overall trend and the assignment of the charge-transfer states in almost all the cases remains the same with the exception found only for $\mathrm{PC}_{2}-\mathrm{RA}_{4}$ and $\mathrm{PC}_{1}-\mathrm{RA}_{3}$ complexes.

Now if we look back into the mechanistic pathway for the PET-RAFT process, we found that the key step is the electron transfer from excited catalyst to the RAFT agents when they are in close proximity. In that situation, an electron is at first excited from the HOMO of the catalyst into its low-lying unoccupied molecular orbital and then electron transfer occurs to the RAFT agents. Following this line of reasoning, for the PheoA complex $\mathrm{PC}_{1}-\mathrm{RA}_{1}$, optical absorption lifts the electron into the LUMO and then it is transferred via perturbative couplings to the LUMO+1 (charge transfer state with amplitude predominantly on the RAFT agent) in the complex. However, for the $\mathrm{PC}_{1}-\mathrm{RA}_{2}$ complex, optical excitation lifts the electron into the LUMO+1 orbital in the excited-state since the LUMO is a charge transfer state. Following the basic rule of thumb of perturbation theory, transfer from the LUMO +1 orbital to the charge transfer LUMO state is expected to be less efficient because of the significantly larger gap between the energies of the two orbitals. In case of xanthate and trithiocarbonates, the first optical excitation occurs from HOMO to LUMO, which would have to be followed by electron transfer from LUMO to the LUMO+2 charge transfer state, or possibly a twostage coupling via LUMO+1. Hence, again because of the larger energy gaps involved between the states we do not expect good rates of electron transfer in these systems. Ultimately, the calculations indicate that the PheoA catalyst should favour activation of the first RAFT agent in the series (CPADB). For the ZnTPP-RAFT agent complexes, the crucial electron transfer would have to occur via coupling from LUMO+1 to LUMO in dithiobenzoates $\left(\mathrm{PC}_{2}-\mathrm{RA}_{1}, \mathrm{PC}_{2}-\mathrm{RA}_{2}\right.$, and $\left.\mathrm{PC}_{2}-\mathrm{RA}_{3}\right)$ while the transfer in xanthate and trithiocarbonate complexes is from LUMO (or LUMO+1 since they are close lying states) to 


\section{WILEY-VCH}

$\mathrm{LUMO}+2$. In all cases excepting $\mathrm{PC}_{2}-\mathrm{RA}_{6}$ and $\mathrm{PC}_{2}-\mathrm{RA}_{5}$, large energy gaps are involved between the optically excited-state and the charge-transfer state, implying slower rates for electron transfer and a marked preference for activation of the last two RAFT agents in the series (BTPA and BSTP) by the ZnTPP catalyst.

For simple visual analysis, we also plotted the energy of the relevant orbitals for all the complexes in Figure 4 at the M05/6-31G(d)+D3 level of theory. The red horizontal lines are the orbitals where we have dominant amplitude on the RAFT agent (representing an intracomplex charge transfer configuration) while the blue lines are those molecular orbitals having amplitude primarily on the catalyst. Neglecting the lowest energy value in these figures, which is that of $\mathrm{HOMO}$, it is quite clear from Figure $4 \mathrm{a}$ that the PheoAdithiobenzoate complexes have much smaller energy gaps for the crucial transitions compared to that of xanthates and trithiocarbonates, implying that perturbative coupling between those orbitals to effect the crucial electron transfer will be more efficient. In contrast, for the ZnTPP complexes, Figure 4b, it is the trithiocarbonates BSTP and BTPA, which have the lowest CT energy gap in the crucial transition when compared with the dithiobenzoates and xanthates. The same selectivity has been observed if we look at the CT energy gap values obtained both in DMSO and in triplet state, which further strengthens the present rationale and supports the experimental reports. Hence, the energy proximity of the initially populated excited orbital and the charge transfer orbital is here suggested as a useful descriptor for indicating the selectivity of the PET-RAFT reaction. These results clearly support the recent experimental findings ${ }^{[4,17]}$ as well as helping to explain them.

In the PET-RAFT process (Scheme 1), the initial RAFT agent was consumed at the early stage of polymerization (generally induction period) to initiate polymer chains (or, macro-RAFT agents). Re-activation of the macro-RAFT agents (i.e., the RAFT agent containing several monomer additions) is then further induced by the catalyst to regenerate radical species. Hence, to comprehensively understand the selectivity of the photoredox 


\section{WILEY-VCH}

catalyst in the PET-RAFT process it is informative to examine the propagation step. Experimentally, we have tested the reactivation of the three dithiobenzoate macro-RAFT agents after addition of methyl methacrylate (MMA) to the RAFT agents, CPADB, CPD, and $\mathrm{CDB}$ in order to probe whether the calalyst selectivity for the initial RAFT agents does or does not apply to macro-RAFT agents. To prepare the macro-RAFT agent with MMA, we have performed conventional RAFT polymerization initiated with $\mathrm{AIBN}$ at $70^{\circ} \mathrm{C}$. After polymerization, we have purified the macro-RAFT agent by three precipitations to yield three macro-RAFT agents prepared with $\mathrm{CPADB}, \mathrm{CPD}$ and $\mathrm{CDB}$. Then, we performed chain extension in the presence of PheoA and MMA with these three different macro-RAFT agents. For instance, the CPD was used to mediate MMA polymerization in the presence of the external radical source AIBN using conventional thermal method instead of PET-RAFT polymerization, generating macro-RAFT agent, CPD-MMA ${ }_{\mathrm{m}}\left(M_{\mathrm{n}}=12990 \mathrm{~g} / \mathrm{mol}\right.$, PDI $=$ 1.10). This macro-RAFT was used to mediate PET-RAFT polymerization of MMA for chain extension, in the presence of PheoA under red light irradiation as shown in Scheme 2. After $12 \mathrm{hr}$ light irradiation, we observed high monomer conversion, yielding polymer with expected molecular weight $\left(M_{\mathrm{n}}=52040 \mathrm{~g} / \mathrm{mol}\right)$ and low polydispersity (1.23). Interestingly, we observed that PheoA could efficiently reactivate the polymerization of all three macroRAFT agents with an excellent control of the molecular weight and PDI. The detailed experimental analyses are provided in the Supporting Information. This result suggests that the $\mathrm{R}$ groups of these dithiobenzoate RAFT agents play an important role in the activation selectivity when PET-RAFT is implemented from the outset. As monomers are sequentially added to produce macro-RAFT agents, the $\mathrm{R}$ group becomes increasingly remote from the catalyst-head group complex. Since all three dithiobenzoate RAFT agents have identical head groups, the selectivity of activation of CPADB compared with CPD and CBD is lost as monomers are successively inserted in to the RAFT agent. 


\section{WILEY-VCH}

To simplify the quantum chemical simulation, monomer addition was limited to just one or two units. Before proceeding to do the excited-state calculations, we performed binding energy analysis for the PheoA-macro-RAFT complexes in their ground-state just to confirm that these macro-RAFT complexes generate energetically favourable structures. Hence, we suggest that they will likely propagate in a pre-complexed configuration via the $\mathrm{S}_{1}$ excited-state, consistent with our electron-transfer mechanism outlined above. We performed excited state TDDFT calculations for the PheoA-macro-RAFT agent complexes. The naming convention as given in Table S1 in the Supporting Information is followed here with addition of a 'p' for propagation with a single inserted monomer unit and 'pp' for propagation with 2 inserted monomeric units in the RAFT agent names. The same analysis is followed here as above for the initiation step. The energy values for the relevant orbitals, i.e., HOMO, LUMO, LUMO+1, and LUMO+2, are tabulated in Table 2. It is clear that for the PheoA complexes, the variations in magnitude of the critical energy-gap descriptor discussed above - which favours CPADB over the other two RAFT agents for the initiation step - decrease markedly after insertion of just one or two monomers into the initial RAFT agents. This is in accord with the experimental observation herein that the photocatalyst is able to activate all of the macro-RAFT CPADB, CPD and CDB agents; whereas the initial activation of the RAFT agents is strongly selective in favour of CPADB.

\section{Conclusion}

This work provides strong theoretical evidence that electron/charge transfer, rather than energy transfer, is the operational mechanism for the PET-RAFT processes studied. ${ }^{[40]} \mathrm{We}$ examined three common energy transfer mechanisms, Förster resonance energy transfer; Dexter electron exchange; and IC/ISC from $S_{1} / T_{1}$ to $S_{0}$ on the photocatalyst followed by vibrational energy transfer to the RAFT agent. Fundamentally due to the substantial barriers to fragmentation of the neutral RAFT agents in both their $S_{0}$ and their $S_{1}$ states, it is highly 


\section{WILEY-VCH}

unlikely that any of these mechanisms can promote fragmentation of the RAFT agent that would lead to polymerisation. Further, none of these mechanisms provide a convincing rationale for the experimentally observed selectivity of the photocatalysts for specific RAFT agents. In contrast, all of the RAFT agents are shown to be unstable with respect to dissociation when in an anionic state, which strongly suggests a mechanism whereby the photocatalysis is mediated via charge transfer states for the studied systems.

Further exploration of the electron/charge transfer mechanism has provided a sound rationalization for the strong specificity of the photoredox catalysts, PheoA and ZnTPP towards RAFT agents incorporating thiocarbonylthio groups. The complex PheoA-CPADB (compared with all other RAFT agents in the series) exhibits the closest energetic proximity between the optical excitation orbital and the low-lying intra-complex charge-transfer orbital - which is an important factor to facilitate perturbative coupling between these two states and thereby mediate the electron transfer. For the complexes between RAFT agents and ZnTPP, the transition between LUMO (or close-lying LUMO+1) and the LUMO +2 intra-complex charge transfer orbital, which occurs for the trithiocarbonate family of RAFT agents, is the most feasible pathway thereby favouring charge transfer for these agents relative to the xanthates and dithiobenzoates.

Our extended calculations indicate that the selectivity associated with the initial polymerisation step decreases significantly after the second and third propagation steps. Consistent with this prediction, we have reported new PET-RAFT experimental studies for the PheoA photocatalyst, which confirm that the selectivity is associated with the initial activation steps.

There is considerable scope for more sophisticated analysis of the charge transfer kinetics and dynamics involved in these very important monomer-selective PET-RAFT processes, providing opportunity for future theoretical investigations. By establishing a simple 


\section{WILEY-VCH}

theoretical rationale for the selectivity based on extensive quantum chemical characterization of the key catalyst-agent complexes, this work provides a foundation for such explorations.

\section{Experimental Section}

Quantum chemical calculations: All the quantum chemical calculations have been implemented in Gaussian 09 suite of programs. In the present investigation, the optimizations and vibrational frequency calculations of the catalysts, PheoA and ZnTPP, and the six RAFT agents in their ground-state have been carried out using M05 meta-GGA functional with the use of 6-31G(d) basis set and Grimme's empirical dispersion with D3 correction. The photoredox catalyst PheoA is asymmetric and hence we performed the ground-state optimizations for the PheoA-RAFT agent complexes using density functional theory (DFT) with and without dispersion correction at both the surfaces.

For the molecular orbital analyses, we performed excited-state time-dependent DFT (TDDFT) calculations for all the catalyst-RAFT agent complexes at M05/6-31G(d)+D3 and B3LYP/6-31G(d)+D3 level of theories. We chose two density functionals for comparison as well as justification purposes. All the TDDFT calculations are carried out predominantly in gas-phase. However, for comparison purpose, we have also carried out implicit solvent phase calculations for one of the catalyst complex, i.e., PheoA-RAFT using integral equation formalism polarizable continuum model (IEFPCM) as implemented in Gaussian 09. Dimethyl sulfoxide (DMSO) is taken as solvent here to mimic the experimental conditions. The calculations have been carried out mostly for the singlet state, while for some complexes we have also done calculations for the triplet excited state. The triplet state optimization for the catalyst-RAFT agents is however very difficult to achieve due to the problem in SCF convergence. We tried to optimize the triplet state initially with the default convergence criterion; however, due to the extremely slow convergence of these complexes, we ultimately had to lower the criterion to $10^{-6}$ in order to yield optimized complexes. 


\section{WILEY-VCH}

Molecular dynamics simulations: The molecular dynamics (MD) calculations were employed using LAMMPS $^{[4]]}$ with the ${ }^{\text {CHARMM }}{ }^{[42-44]}$ compatible force field CGENFF. ${ }^{[45-47]}$ The CGENFF force field ${ }^{[45]}$ was used to parameterize the catalyst PheoA; RAFT agents CPADB \& BTPA; and the solvent, DMSO, and was shown to be effective in predicting several categories of the system properties. ${ }^{[48,49]}$ The molecular model for the catalyst, agents, and the solvent considered was designed with the 3D builder in MAESTRO Schrodinger 2.8.013, then input to the CGENFF webserver ${ }^{[46]}$ providing the atom types, atomic charges, bond, and dihedral parameters. The relative molecular topology has been generated with in-house code, following the CGENFF force field procedure ${ }^{[42-44]}$ System construction and validation of all the molecules was performed employing our established strategies. ${ }^{[50,51]}$ The initial configurations of one typical simulation includes one agent, one catalyst, and ten randomly distributed solvent molecules, arranged in a periodic simulation box of size 2.7 × 2.7 x 2.7 $\mathrm{nm}^{3}$, using PACKMOL. ${ }^{[52]}$ The van der Waals interactions are truncated at the cut off distance of $1.2 \mathrm{~nm}$ with a smooth switching function. ${ }^{[41]}$ The Particle Mesh Ewald ${ }^{[53]}$ method is used to calculate the full electrostatic interactions with a grid spacing of $1 \AA$, computed every step. The temperature is kept constant with a Nose-Hoover thermostat and the velocity-Verlet integration scheme ${ }^{[54]}$ is used to evolve the atom positions with 1 fs time step. The system is minimized for 1000 steps, and then equilibrated for further $10^{5}$ steps employing the NVT ensemble. It is important to note that to mimic the experimental conditions and to match the excitation energy obtained for PheoA at M05/6-31G(d) level of theory, the effective temperature of the catalyst is set to $\mathrm{T}=523 \mathrm{~K}$ and the temperature of agents and the solvent is set to $\mathrm{T}=293 \mathrm{~K}$. Hence, $\mathrm{N}$ and $\mathrm{V}$ are fixed parameters of the simulations, and the temperature is also fixed but different for the catalyst, which can be implemented in LAMMPS integrating the equation of motion separately for the catalyst on one hand, and the solvent $\&$ agent ${ }^{[41]}$ on the other. After $300 \mathrm{ps,}$, we pass from fixed NVT to fixed NVE conditions, switching off the independent thermostat applied to the catalyst and allowing the whole system to evolve under 


\section{WILEY-VCH}

the NVE conditions for a further 150 ps. This allows us to examine the dissipation of the vibrational excitation in the catalyst into the surrounding RAFT agent and solvent molecules as ultimately an equilibrium distribution is attained.

\section{Supporting Information}

Supporting Information is available from the Wiley Online Library or from the author.

\section{Acknowledgements}

This research was undertaken with computational resources provided by the Australian National Computational Infrastructure (NCI) facility at the Australian National University, allocated through the National Computational Merit Allocation Scheme as well as the UNSW partner share on the NCI.

\section{Conflict of Interest}

The authors declare no conflict of interest.

Received: ((will be filled in by the editorial staff))

Revised: ((will be filled in by the editorial staff)) Published online: ((will be filled in by the editorial staff))

\section{References}

[1] G. Ciamician, Science 1912, 36, 385.

[2] D. M. Schultz, T. P. Yoon, Science 2014, 343, 1239176.

[3] N. J. Turro, V. Ramamurthy, J. C. Scaiano, Modern Molecular Photochemistry of Organic Molecules, University Science Books, Sausalito, CA, USA 2010.

[4] J. Xu, S. Shanmugam, C. Fu, K. -F. Aguey-Zinsou, C. Boyer, J. Am. Chem. Soc. 2016, $138,3094$.

[5] C. K. Prier, D. A. Rankic, D. W. C. MacMillan, Chem. Rev. 2013, 113, 5322.

[6] J. M. R. Narayanam, C. R. J. Stephenson, Chem. Soc. Rev. 2011, 40, 102.

[7] N. Corrigan, S. Shanmugam, J. Xu, C. Boyer, Chem. Soc. Rev. 2016, 45, 6165.

[8] S. Shanmugam, J. Xu, C. Boyer, Angew. Chem. Int. Ed. 2016, 55, 1036.

[9] S. Shanmugam, C. Boyer, Science 2016, 352, 1053. 


\section{WILEY-VCH}

[10] C. Fu, J. Xu, C. Boyer, Chem. Commun. 2016, 52, 7126.

[11] T. G. McKenzie, Q. Fu, M. Uchiyama, K. Satoh, J. Xu, C. Boyer, M. Kamigaito, G. G. Qiao, $A d v . S c i .2016,1500394$.

[12] J. L. Jeffrey, F. R. Petronijević, D. W. C. MacMillan, J. Am. Chem. Soc. 2015, 137, 8404.

[13] J. J. Devery III, C. R. J. Stephenson, Nature 2015, 519, 42.

[14] N. A. Romero, K. A. Margrey, N. E. Tay, D. A. Nicewicz, Science 2015, 349, 1326.

[15] P. Xiao, J. Zhang, F. Dumur, M. A. Tehfe, F. Morlet-Savary, B. Graff, D. Gigmes, J. P. Fouassier, J. Lalevée, Prog. Polym. Sci. 2015, 41, 32.

[16] J. T. Xu, K. Jung, A. Atme, S. Shanmugam, C. Boyer, J. Am. Chem. Soc. 2014, 136, 5508.

[17] S. Shanmugam, J. Xu, C. Boyer, J. Am. Chem. Soc. 2015, 137, 9174.

[18] S. Shanmugam, J. Xu, C. Boyer, Chem. Sci. 2015, 6, 1341.

[19] M. Ciftci, Y. Yoshikawa, Y. Yagci, Angew. Chem. Int. Ed. 2017, 56, 519.

[20] X. Pan, M. A. Tasdelen, J. Laun, T. Junkers, Y. Yagci, K. Matyjaszewski, Prog. Polym. Sci. 2016, 62, 73.

[21] A. Allushi, S. Jockusch, G. Yilmaz, Y. Yagci, Macromolecules 2016, 49, 7785.

[22] L. P. da M. Costa, T. G. McKenzie, K. N. Schwarz, Q. Fu, G. G. Qiao, ACS Macro Lett. 2016, 5, 1287.

[23] B. Wenn, T. Junkers, Macromolecules 2016, 49, 6888.

[24] J. Niu, D. J. Lunn, A. Pusuluri, J. I. Yoo, M. A. O’Malley, S. Mitragotri, H. T. Soh, C. J. Hawker, Nat. Chem. 2017, 9, 537.

[25] M. Chen, S. Deng, Y. Gu, J. Lin, M. J. MacLeod, J. A. Johnson, J. Am. Chem. Soc. 2017, 139, 2257. 


\section{WILEY-VCH}

[26] M. Chen, Y. Gu, A. Singh, M. Zhong, A. M. Jordan, S. Biswas, L. T. J. Korley, A. C. Balazs, J. A. Johnson, ACS Cent. Sci. 2017, 3, 124.

[27] A. Singh, O. Kuksenok, J. A. Johnson, A. C. Balazs, Soft Matter, 2017, 13, 1978.

[28] M. Chen, M. Zhong, J. A. Johnson, Chem. Rev. 2016, 116, 10167.

[29] J. Yeow, S. Shanmugam, N. Corrigan, R. P. Kuchel, J. Xu, C. Boyer, Macromolecules 2016, 49, 7277.

[30] G. Ng, J. Yeow, R. Chapman, N. Isahak, E. Wolvetang, J. J. Cooper-White, C. Boyer, Macromolecules 2018, 51, 7600.

[31] Th. Förster, Discussion Faraday Soc. 1959, 27, 7.

[32] D. L. Dexter, J. Chem. Phys. 1953, 21, 836.

[33] J. Xu, S. Shanmugam, H. T. Duong, C. Boyer, Polym. Chem. 2015, 6, 5615.

[34] Y. Zhao, N. E. Schultz, D. G. Truhlar, J. Chem. Phys. 2005, 123, 161103.

[35] S. Grimme, J. Antony, S. Ehrlich, H. Krieg, J. Chem. Phys. 2010, 132, 154104.

[36] P. Maximiano, P. V. Mendonça, J. R. C. Costa, N. L. Haworth, A. C. Serra, T. Guliashvili, M. L. Coote, J. F. J. Coelho, Macromolecules 2016, 49, 1597.

[37] Gaussian 09, Revision D.01, M. J. Frisch, G. W. Trucks, H. B. Schlegel, G. E. Scuseria, M. A. Robb, J. R. Cheeseman, G. Scalmani, V. Barone, G. A. Petersson, H. Nakatsuji, X. Li, M. Caricato, A. Marenich, J. Bloino, B. G. Janesko, R. Gomperts, B. Mennucci, H. P. Hratchian, J. V. Ortiz, A. F. Izmaylov, J. L. Sonnenberg, D. Williams-Young, F. Ding, F. Lipparini, F. Egidi, J. Goings, B. Peng, A. Petrone, T. Henderson, D. Ranasinghe, V. G. Zakrzewski, J. Gao, N. Rega, G. Zheng, W. Liang, M. Hada, M. Ehara, K. Toyota, R. Fukuda, J. Hasegawa, M. Ishida, T. Nakajima, Y. Honda, O. Kitao, H. Nakai, T. Vreven, K. Throssell, J. A. Montgomery, Jr., J. E. Peralta, F. Ogliaro, M. Bearpark, J. J. Heyd, E. Brothers, K. N. Kudin, V. N. Staroverov, T. Keith, R. Kobayashi, J. Normand, K. Raghavachari, A. Rendell, J. C. Burant, S. S. Iyengar, J. Tomasi, M. Cossi, J. M. Millam, M. 


\section{WILEY-VCH}

Klene, C. Adamo, R. Cammi, J. W. Ochterski, R. L. Martin, K. Morokuma, O. Farkas, J. B. Foresman, D. J. Fox, Gaussian, Inc., Wallingford, CT, USA 2016.

[38] A. D. Becke, J. Chem. Phys. 1993, 98, 5648.

[39] C. Lee, W. Yang, R. G. Parr, Phys. Rev. B 1988, 37785.

[40] N. Corrigan, J. Xu, C. Boyer, X. Allonas, ChemPhotoChem 2019, 3, 1.

[41] S. Plimpton, J. Comp. Phys. 1995, 117, 1.

[42] R. B. Best, X. Zhu, J. Shim, P. E. M. Lopes, J. Mittal, M. Feig, A. D. MacKerell Jr, J. Chem. Theor. Comput. 2012, 8, 3257.

[43] A. D. MacKerell, Jr., D. Bashford, M. Bellott, R. L. Dunbrack, Jr., J. D. Evanseck, M. J. Field, S. Fischer, J. Gao, H. Guo, S. Ha, D. Joseph-McCarthy, L. Kuchnir, K. Kuczera, F. T. K. Lau, C. Mattos, S. Michnick, T. Ngo, D. T. Nguyen, B. Prodhom, W. E. Reiher, III, B. Roux, M. Schlenkrich, J. C. Smith, R. Stote, J. Straub, M. Watanabe, J. WiórkiewiczKuczera, D. Yin, M. Karplus, J. Phys. Chem. B 1998, 102, 3586.

[44] A. D. MacKerell Jr, M. Feig, C. L. Brooks III, J. Comp. Chem. 2004, 25, 1400.

[45] K. Vanommeslaeghe, E. Hatcher, C. Acharya, S. Kundu, S. Zhong, J. Shim, E. Darian, O. Guvench, P. Lopes, I. Vorobyov, A. D. Mackerell Jr. J. Comput. Chem. 2010, 31, 671.

[46] K. Vanommeslaeghe, A. D. Mackerell Jr, J. Chem. Inf. Model. 2012, 52, 3144.

[47] K. Vanommeslaeghe, E. P. Raman, A. D. MacKerell Jr, J. Chem. Inf. Model. 2012, 52,3155 .

[48] C. P. Schneider, D. Shukla, B. L. Trout, PlosOne 2011, 6, e27665.

[49] S. Kanchi, G. Suresh, U. D. Priyakumar, K. G. Ayappa, P. K. Maiti, J. Phys. Chem. $B$ 2015, 119, 12990.

[50] S. De Luca, P. Seal, D. Ouyang, H. S. Parekh, S. K. Kannam, S. C. Smith, J. Phys. Chem. B 2016, 120, 5732.

[51] S. De Luca, F. Chen, P. Seal, M. H. Stenzel, S. C. Smith, Biomacromolecules, 2017, 18,3665 . 


\section{WILEY-VCH}

[52] L. Martínez, R. Andrade, E. G. Birgin, J. M. Martínez, J. Comput. Chem. 2009, 30, 2157.

[53] T. Darden, D. York, L. Pedersen, J. Chem. Phys. 1993, 98, 10089.

[54] M. P. Allen, D. J. Tildesley, Computer simulation of liquids, Oxford University Press, New York, USA 1987. 


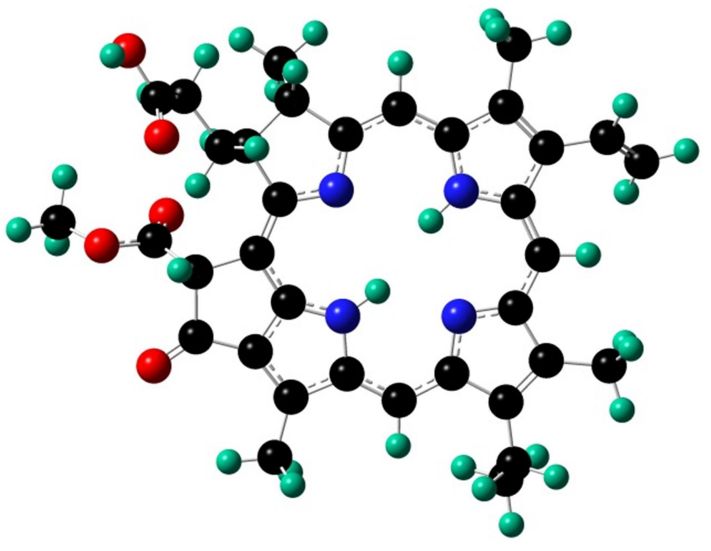

(a)

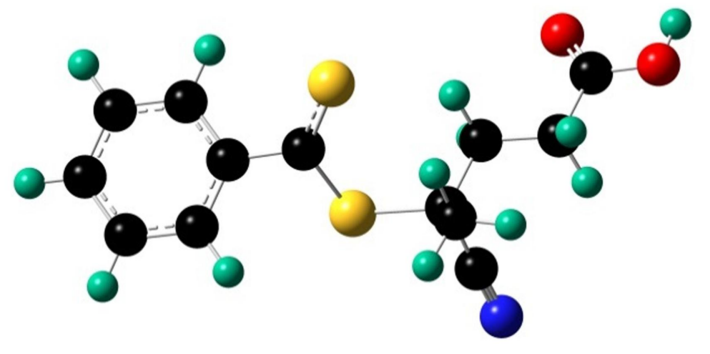

(c)

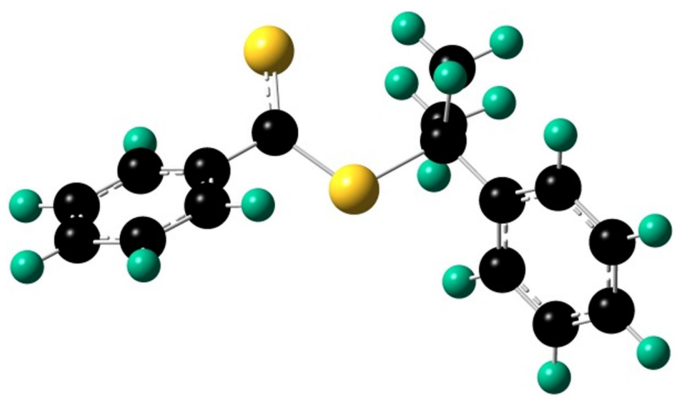

(e)

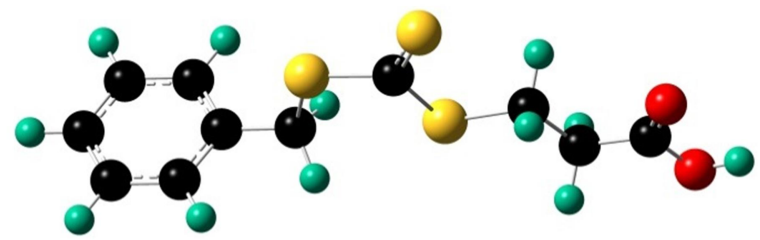

(g)

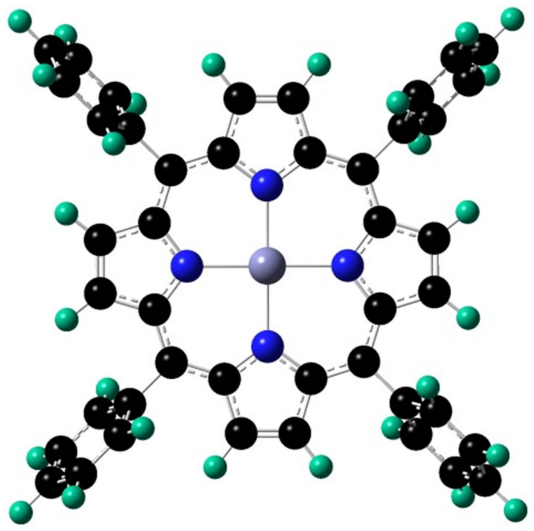

(b)

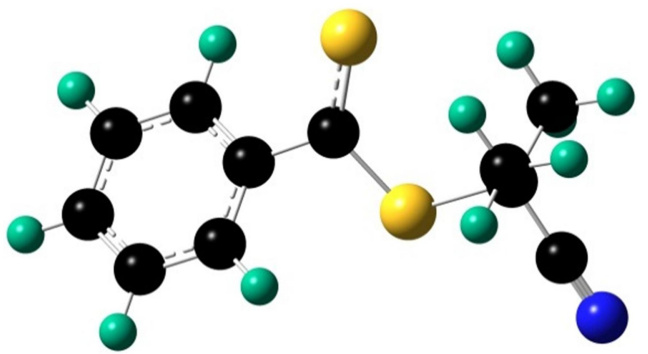

(d)

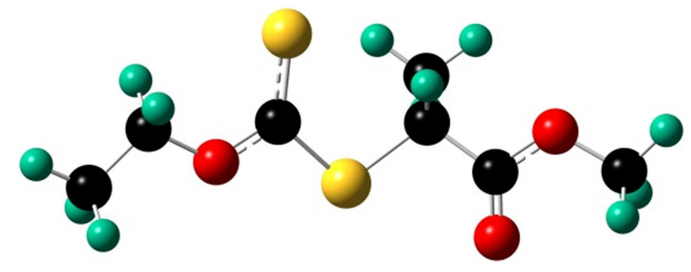

(f)

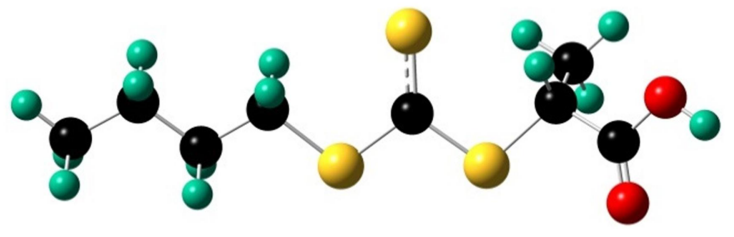

(h)

Figure 1. M05/6-31G(d) + D3 optimized geometries of a) pheophorbide $a$ (PheoA), b) zinc tetraphenylporphine (ZnTPP), c) 4-cyanopentanoic acid dithiobenzoate (CPADB), d) 2cyano-2-propyl benzodithioate (CPD), e) cumyl dithiobenzoate (CDB), f) methyl 2[(ethoxycarbonothioyl)sulfanyl] propanoate (Xanthate), g) 3-benzylsulfanylthiocarbonylthiosulfanyl propionic acid (BSTP), and h) 2-( $n$-butyltrithiocarbonate)-propionic acid (BTPA). Colour convention: Carbon: black, Hydrogen: Teal, Nitorgen: Blue, Oxygen: Red, and Sulphur: Yellow. 


\section{WILEY-VCH}

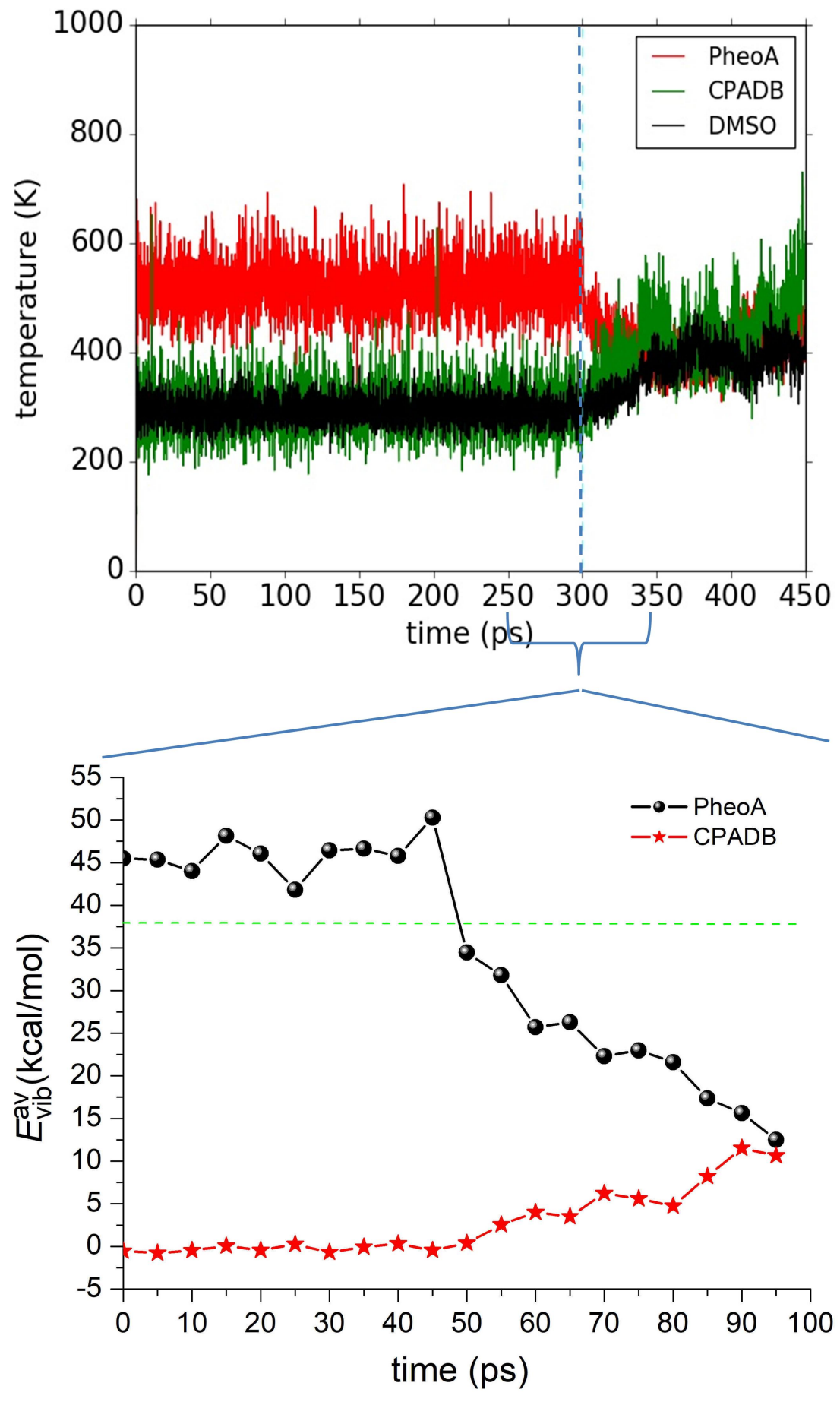

(a) 


\section{WILEY-VCH}
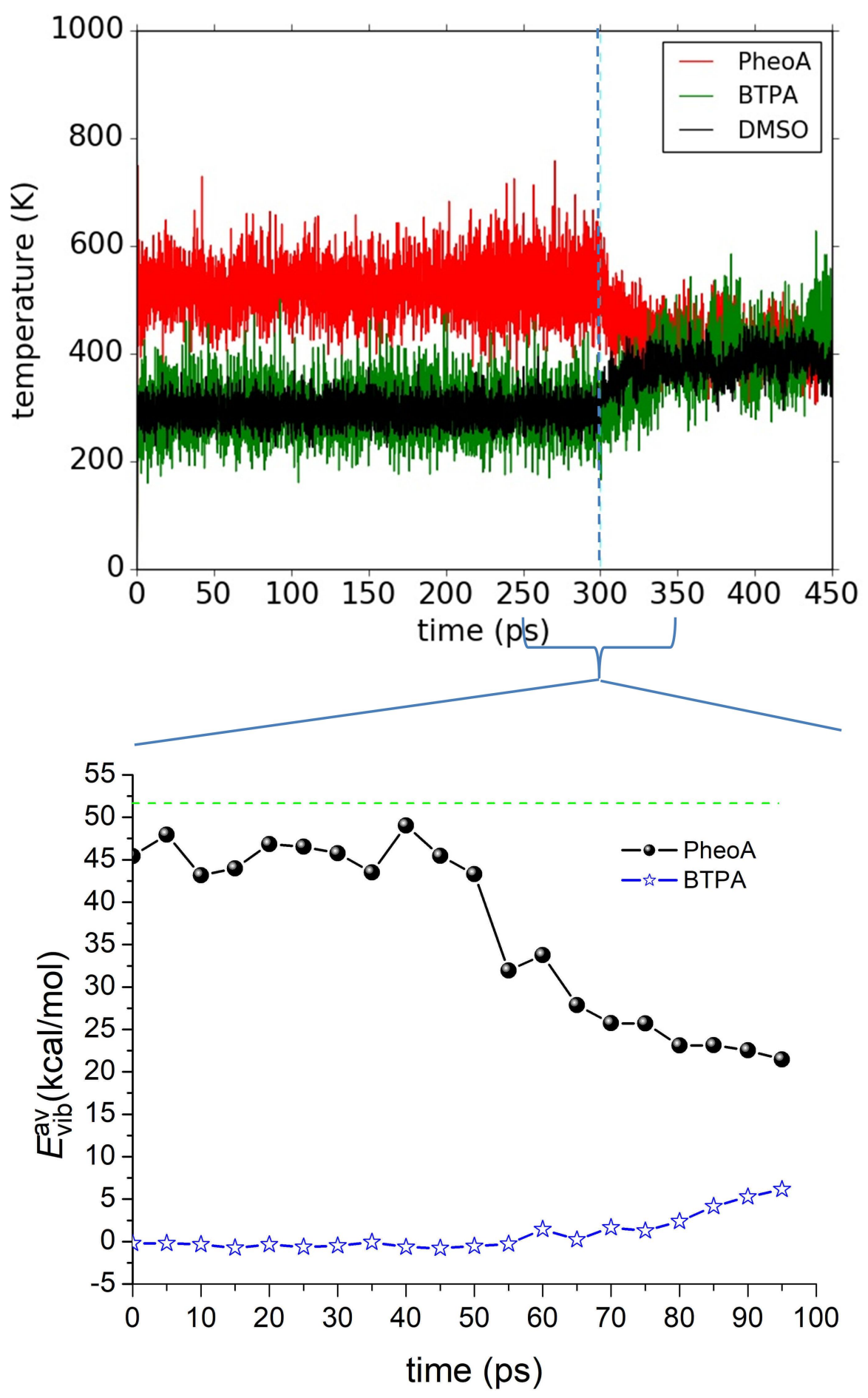

(b)

Figure 2. The variation of temperature (in K) with time for a) PheoA-CPADB and b) PheoABTPA complexes in DMSO. The change in the corresponding vibrationally average thermal energy curve for the zoom-in portion $(250-350 \mathrm{ps})$ of the T-t plot is also provided for both the complexes. 


\section{WILEY-VCH}

Complex

$\mathrm{PC}_{1}-\mathrm{RA}_{1}$

$\mathrm{PC}_{2}-\mathbf{R A}_{6}$
LUMO

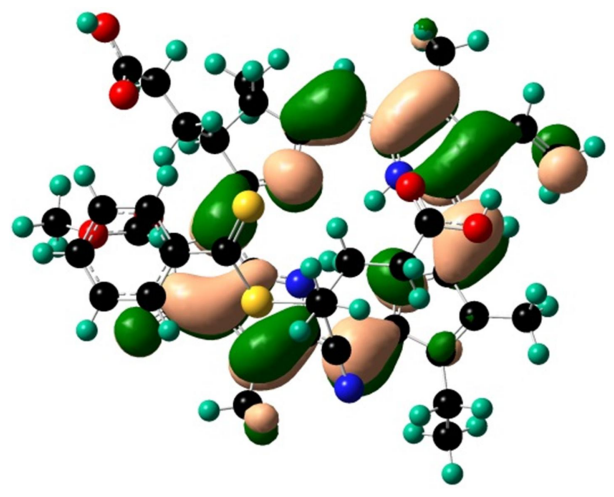

LUMO

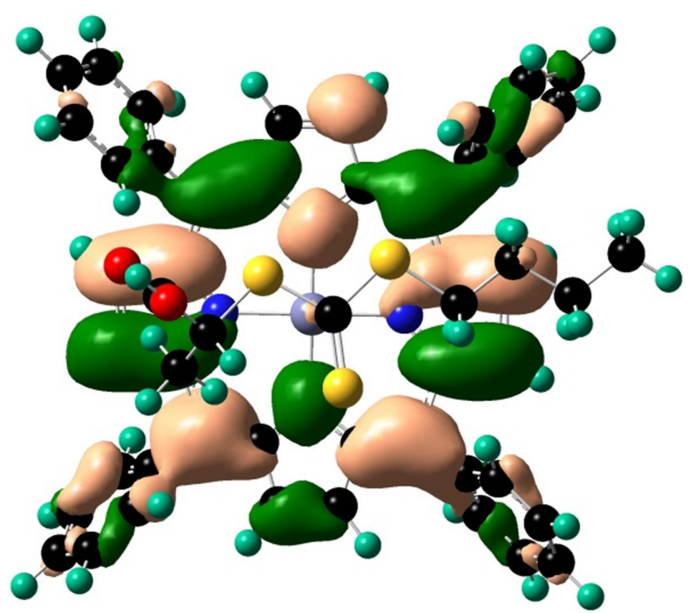

LUMO + 1

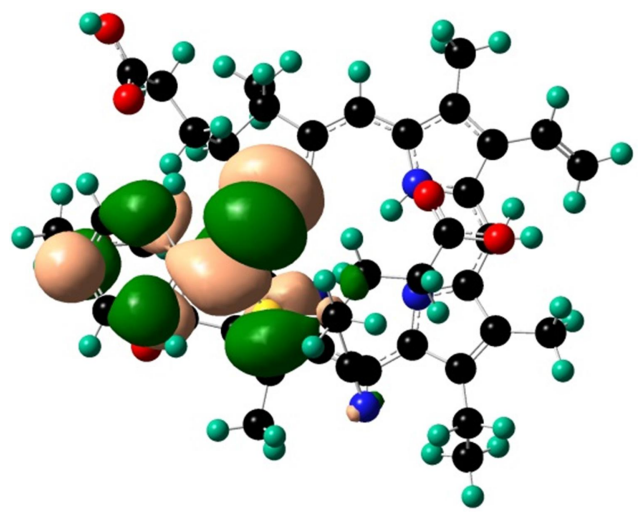

LUMO + 2

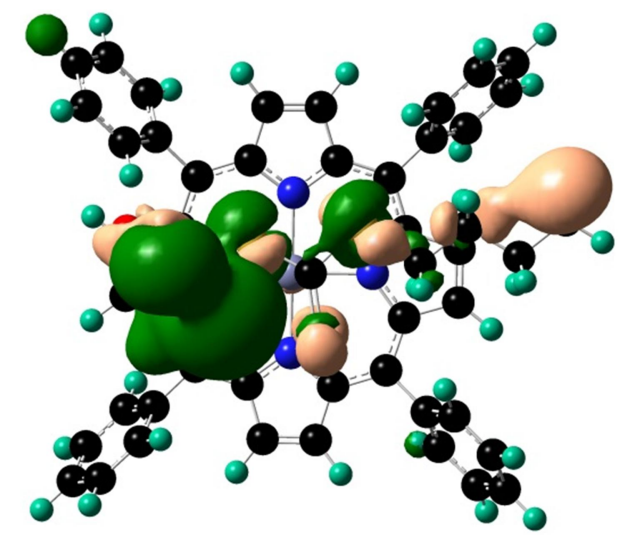

Figure 3. Molecular orbitals for the crucial transitions observed in two representative complexes under investigation at M05/6-31G(d) + D3 level of theory. The LUMO and LUMO +1 orbitals are for the complexes formed by PheoA with CPADB (PheoA-CPADB: $\mathrm{PC}_{1}-\mathrm{RA}_{1}$ ) whereas it's the LUMO and LUMO +2 orbitals for the complexes that are formed by ZnTPP with BTPA (ZnTPP-BTPA: $\mathrm{PC}_{2}-\mathrm{RA}_{6}$ ). In these figures, the orbitals those are presented have the dominant contributions from the catalysts, PheoA and ZnTPP and from the two RAFT agents. 


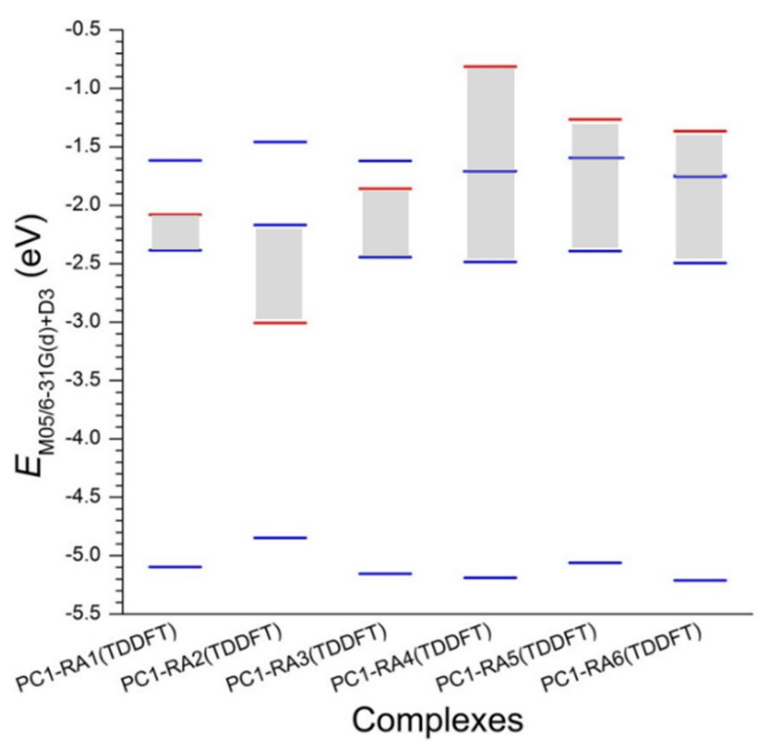

(a)

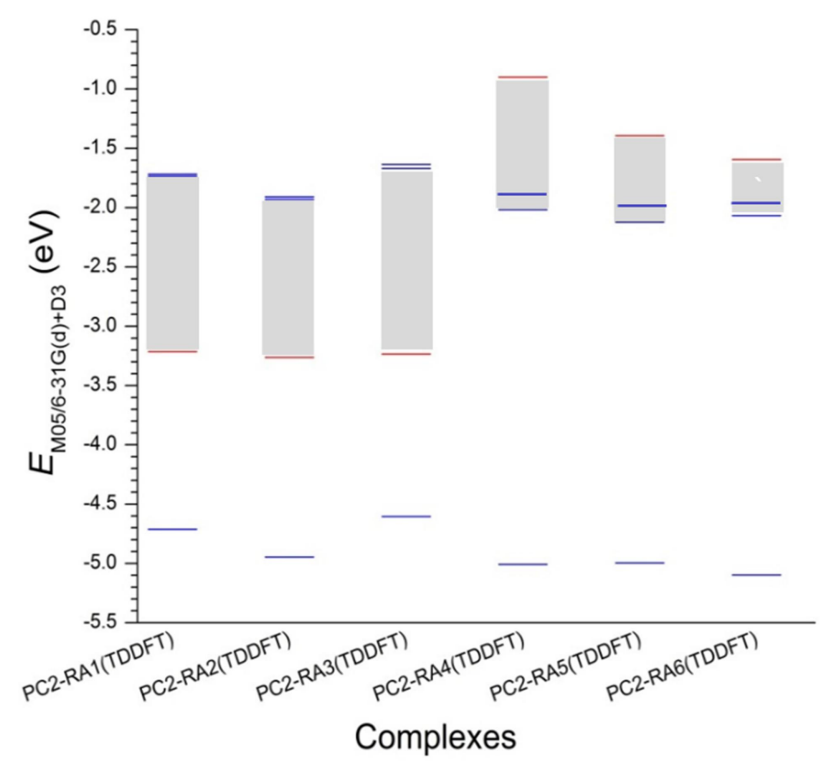

(b)

Figure 4. The energies for the relevant molecular orbitals, i.e., HOMO, LUMO, LUMO+1, and LUMO +2 of all the complexes formed between RAFT agents and the photoredox catalysts (a) PheoA and (b) ZnTPP in the first excited-state obtained at M05/6-31G(d) + D3 level of theory. In each of these figures, the red horizontal lines correspond to the charge transfer molecular orbitals with major contributions from the RAFT agents. The grey shaded areas represent the crucial transition energy gap (see also Table 2). 

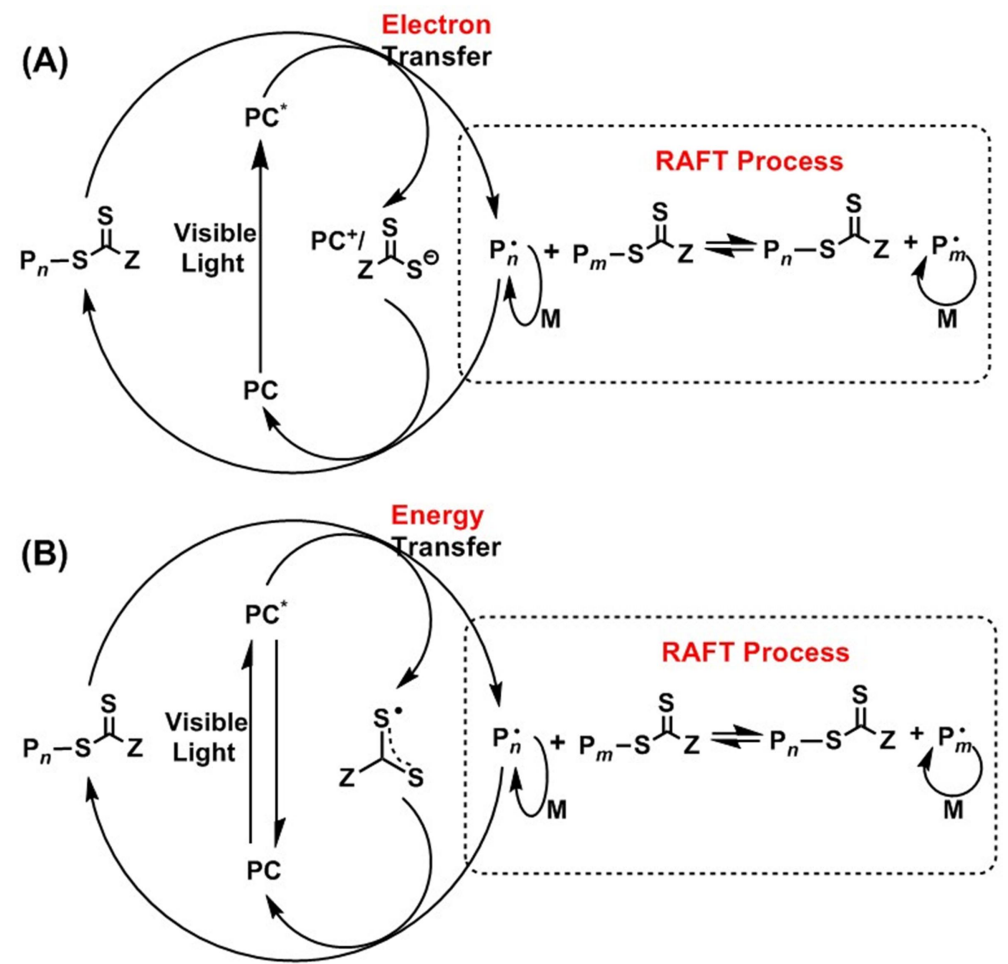

Scheme 1. Proposed mechanism for photoinduced electron/energy transfer-reversible addition-fragmentation chain transfer (PET-RAFT) polymerization in the presence of photocatalyst: A) electron transfer and B) energy transfer mechanism. PC: photocatalyst.

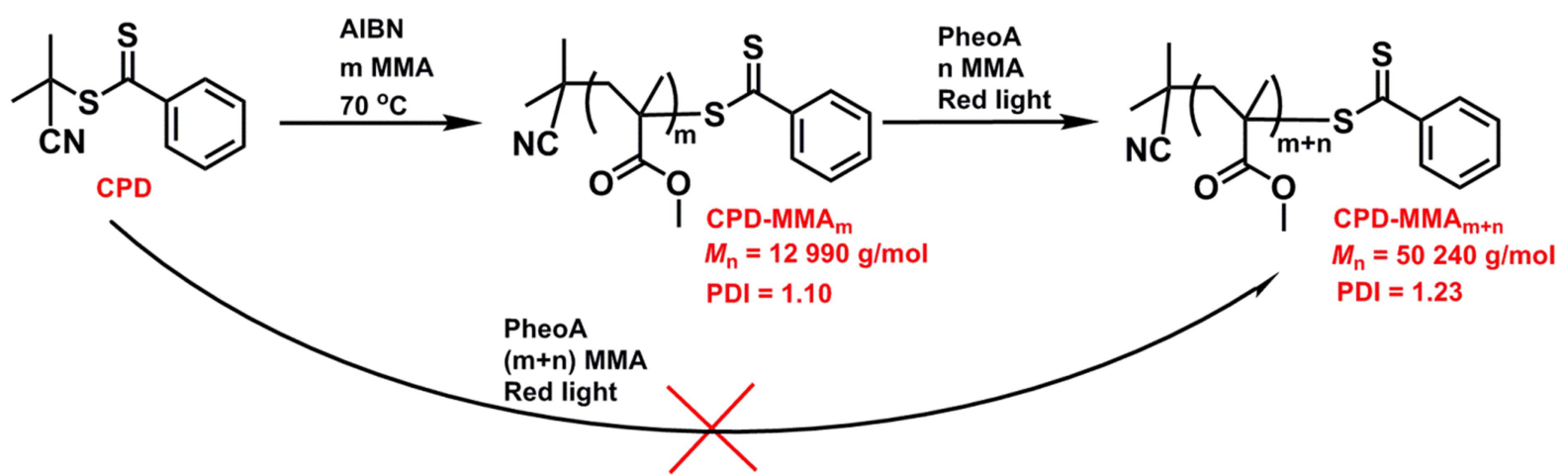

Scheme 2. Macro-RAFT agent prepared from CPD using conventional thermal polymerization can be re-activated for PET-RAFT polymerization using PheoA as photocatalyst. 
WILEY-VCH

Table 1. RAFT agent fragmentation energies.

\begin{tabular}{cccc}
\hline RAFT agent & $\begin{array}{c}\mathrm{S}_{0}-\mathrm{S}_{1}{ }^{a)} \\
(\mathrm{kcal} / \mathrm{mol})\end{array}$ & $\begin{array}{c}\mathrm{S}_{0} \text { barrier to } \\
\text { dissociation }^{\text {b) }}(\mathrm{kcal} / \mathrm{mol})\end{array}$ & $\begin{array}{c}\mathrm{S}_{1} \text { barrier to } \\
\text { dissociation }^{\mathrm{c}}\left(\mathrm{kcal}^{\prime} / \mathrm{mol}\right)\end{array}$ \\
\hline CPADB & 38.80 & 37.88 & 99.10 \\
CPD & 38.94 & 38.18 & 100.31 \\
CDB & 38.03 & 40.96 & 87.96 \\
Xanthate & 60.66 & 53.64 & 53.84 \\
BSTP & 51.51 & 65.10 & 121.73 \\
BTPA & 61.88 & 51.54 & 50.64 \\
\hline
\end{tabular}

${ }^{\text {a) }}$ Energy difference between the 1 st excited state and the ground state; ${ }^{\text {b) }}$ Dissociation barrier in the ground state; ${ }^{c)}$ Dissociation barrier in the 1st excited state 
WILEY-VCH

Table 2. Detailed orbital energy analysis (in eV) of all the complexes studied in the present work.

\begin{tabular}{|c|c|c|c|c|c|c|c|c|}
\hline$\#$ & Complex & RAFT agents & HOMO & LUMO & LUMO + 1 & LUMO + 2 & Crucial Transition & $\begin{array}{c}\text { Uphill(U)/ } \\
\text { Downhill(D) }\end{array}$ \\
\hline \multicolumn{9}{|c|}{ PheoA-RAFT } \\
\hline \multicolumn{9}{|c|}{ Initiation Step } \\
\hline $\begin{array}{l}1 \\
2 \\
3 \\
4 \\
5 \\
6\end{array}$ & $\begin{array}{l}\mathrm{PC}_{1}-\mathrm{RA}_{1}(\mathrm{M} 05)^{a} \\
\mathrm{PC}_{1}-\mathrm{RA}_{2}(\mathrm{M} 05) \\
\mathrm{PC}_{1}-\mathrm{RA}_{3}(\mathrm{M} 05) \\
\mathrm{PC}_{1}-\mathrm{RA}_{4}(\mathrm{M} 05) \\
\mathrm{PC}_{1}-\mathrm{RA}_{5}(\mathrm{M} 05) \\
\mathrm{PC}_{1}-\mathrm{RA}_{6}(\mathrm{M} 05)\end{array}$ & $\begin{array}{l}\text { CPADB } \\
\text { CPD } \\
\text { CDB } \\
\text { Xanthate } \\
\text { BSTP } \\
\text { BTPA }\end{array}$ & $\begin{array}{l}-5.096 \\
-4.847 \\
-5.154 \\
-5.188 \\
-5.06 \\
-5.21\end{array}$ & $\begin{array}{l}-2.385 \\
-3.006 \\
-2.444 \\
-2.484 \\
-2.391 \\
-2.493\end{array}$ & $\begin{array}{l}-2.079^{\circ} \\
-2.168 \\
-1.858 \\
-1.708 \\
-1.594 \\
-1.748\end{array}$ & $\begin{array}{l}-1.617 \\
-1.458 \\
-1.62 \\
-0.813 \\
-1.266 \\
-1.365 \\
\end{array}$ & $\begin{array}{l}0.306 \\
0.838 \\
0.586 \\
1.671 \\
1.125 \\
1.128\end{array}$ & $\begin{array}{l}U \\
D \\
U \\
U \\
U \\
U\end{array}$ \\
\hline $\begin{array}{c}7 \\
8 \\
9 \\
10 \\
11 \\
12\end{array}$ & $\begin{array}{l}\mathrm{PC}_{1}-\mathrm{RA}_{1}(\mathrm{~B} 3 L Y P) \\
\mathrm{PC}_{1}-\mathrm{RA}_{2} \text { (B3LYP) } \\
\mathrm{PC}_{1}-\mathrm{RA}_{3} \text { (B3LYP) } \\
\mathrm{PC}_{1}-\mathrm{RA}_{4} \text { (B3LYP) } \\
\mathrm{PC}_{1}-\mathrm{RA}_{5} \text { (B3LYP) } \\
\mathrm{PC}_{1}-\mathrm{RA}_{6} \text { (B3LYP) }\end{array}$ & $\begin{array}{l}\text { CPADB } \\
\text { CPD } \\
\text { CDB } \\
\text { Xanthate } \\
\text { BSTP } \\
\text { BTPA }\end{array}$ & $\begin{array}{l}-4.929 \\
-4.676 \\
-4.589 \\
-5.002 \\
-4.904 \\
-5.044\end{array}$ & $\begin{array}{l}-2.520 \\
-3.223 \\
-2.780 \\
-2.603 \\
-2.537 \\
-2.623\end{array}$ & $\begin{array}{l}-2.387 \\
-2.331 \\
-2.495 \\
-1.882 \\
-1.804 \\
-1.946\end{array}$ & $\begin{array}{l}-1.809 \\
-1.642 \\
-1.794 \\
-1.147 \\
-1.516 \\
-1.638 \\
\end{array}$ & $\begin{array}{l}0.132 \\
0.892 \\
2.094 \\
1.456 \\
1.021 \\
0.985\end{array}$ & $\begin{array}{l}U \\
D \\
D \\
U \\
U \\
U\end{array}$ \\
\hline \multicolumn{9}{|c|}{ Propagation Step } \\
\hline $\begin{array}{l}13 \\
14 \\
15\end{array}$ & $\begin{array}{l}\mathrm{PC}_{1}-\mathrm{RA}_{1 p}(\mathrm{M} 05) \\
\mathrm{PC}_{1}-\mathrm{RA}_{2 p}(\mathrm{M} 05) \\
\mathrm{PC}_{1}-\mathrm{RA}_{3 p}(\mathrm{M} 05)\end{array}$ & $\begin{array}{l}\text { CPADB-MMA } \\
\text { CPD-MMA } \\
\text { CDB-MMA }\end{array}$ & $\begin{array}{l}-5.161 \\
-4.595 \\
-5.220\end{array}$ & $\begin{array}{l}-2.434 \\
-2.954 \\
-2.518\end{array}$ & $\begin{array}{l}-1.720 \\
-1.931 \\
-1.763\end{array}$ & $\begin{array}{l}-1.692 \\
-1.241 \\
-1.578\end{array}$ & $\begin{array}{l}0.714 \\
1.024 \\
0.940\end{array}$ & $\begin{array}{l}U \\
D \\
U\end{array}$ \\
\hline $\begin{array}{l}16 \\
17 \\
18\end{array}$ & $\begin{array}{l}\mathrm{PC}_{1}-\mathrm{RA}_{1 \mathrm{p}} \text { (B3LYP) } \\
\mathrm{PC}_{1}-\mathrm{RA}_{2 \mathrm{p}} \text { (B3LYP) } \\
\mathrm{PC}_{1}-\mathrm{RA}_{3 \mathrm{p}} \text { (B3LYP) }\end{array}$ & $\begin{array}{l}\text { CPADB-MMA } \\
\text { CPD-MMA } \\
\text { CDB-MMA }\end{array}$ & $\begin{array}{l}-4.987 \\
-4.462 \\
-5.043\end{array}$ & $\begin{array}{l}-2.565 \\
-3.187 \\
-2.642\end{array}$ & $\begin{array}{l}-2.015 \\
-2.146 \\
-1.946\end{array}$ & $\begin{array}{l}-1.879 \\
-1.502 \\
-1.876\end{array}$ & $\begin{array}{l}0.550 \\
1.041 \\
0.766\end{array}$ & $\begin{array}{l}U \\
D \\
U\end{array}$ \\
\hline $\begin{array}{l}19 \\
20 \\
21\end{array}$ & $\begin{array}{l}\mathrm{PC}_{1}-\mathrm{RA}_{1 \mathrm{pp}}(\mathrm{M} 05) \\
\mathrm{PC}_{1}-\mathrm{RA}_{2 \mathrm{pp}}(\mathrm{M} 05) \\
\mathrm{PC} \mathrm{C}_{1}-\mathrm{RA}_{3 \mathrm{pp}}(\mathrm{M} 05)\end{array}$ & $\begin{array}{l}\text { CPADB-(MMA) })_{2} \\
\text { CPD-(MMA) })_{2} \\
\text { CDB-(MMA) })_{2}\end{array}$ & $\begin{array}{r}-4.966 \\
-4.752 \\
-5.289\end{array}$ & $\begin{array}{l}-2.758 \\
-2.737 \\
-2.596\end{array}$ & $\begin{array}{l}-1.802 \\
-2.069 \\
-1.809\end{array}$ & $\begin{array}{l}-1.191 \\
-1.389 \\
-1.697\end{array}$ & $\begin{array}{l}0.611 \\
0.669 \\
0.899\end{array}$ & $\begin{array}{l}U \\
D \\
U\end{array}$ \\
\hline
\end{tabular}

Initiation Step

$\begin{array}{lc}\mathrm{PC}_{2}-\mathrm{RA}_{1}(\mathrm{M} 05) & \mathrm{CPADB} \\ \mathrm{PC}_{2}-\mathrm{RA}_{2}(\mathrm{M} 05) & \mathrm{CPD} \\ \mathrm{PC}_{2}-\mathrm{RA}_{3}(\mathrm{M} 05) & \text { CDB } \\ \mathrm{PC}_{2}-\mathrm{RA}_{4}(\mathrm{M} 05) & \text { Xanthate } \\ \mathrm{PC}_{2}-\mathrm{RA}_{5}(\mathrm{M} 05) & \text { BSTP } \\ \mathrm{PC}_{2}-\mathrm{RA}_{6}(\mathrm{M} 05) & \text { BTPA }\end{array}$

-4.713
-4.947
-4.604
-5.007
-4.996
-5.098

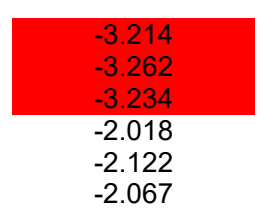
$-1.734$
$-1.93$
$-1.877$
$-1.983$

BSTP

$-5.098$

$-2.067$

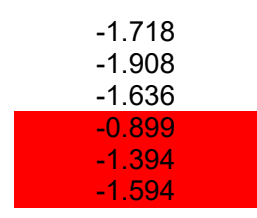

1.48
1.332
1.564
1.119
0.728
0.473

$D$
$D$
$D$
$U$
$U$
$U$ 


CPADB
CPD
CDB
Xanthate
BSTP
BTPA

-4.549
-4.559

$-4.557$

$-4.549$

$-4.421$

$-4.732$

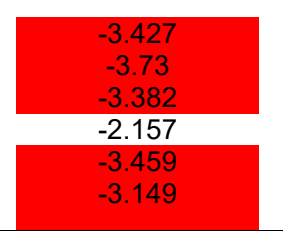

$-1.89$

$-1.952$

-1.952
-1.832

$-1.984$

-1.943
-1.995

${ }^{\text {a) }}$ The parentheses in each row goes like this: Density Functional/6-31G(d)+D3 with the Density Functional $\equiv$ M05/B3LYP; ${ }^{\text {b) }}$ The energy values highlighted in red are the orbitals where we have the major contributions from the RAFT agents. 


\section{WILEY-VCH}

The present work provides a foundation for understanding the strong selectivity of photoredox catalysts, PheoA and ZnTPP towards RAFT agents containing thiocarbonylthio groups. This in turn has successfully been used to report and design controlled polymeric architectures thereby opening up new avenues towards polymer synthesis with monomer sequences, tailored for different applications.

\section{Exceptioal selectivity of photoredox catalyst}

Prasenjit Seal,* Jiangtao Xu, Sergio De Luca, Cyrille Boyer, and Sean C. Smith*

\section{Unravelling Photocatalytic Mechanism and Selectivity in PET-RAFT Polymerization}

ToC figure

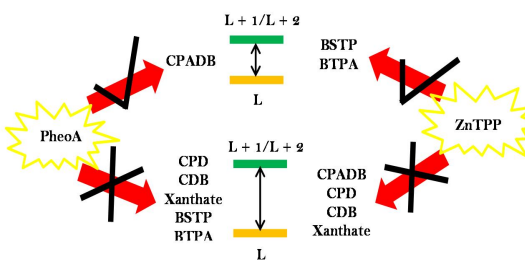


Copyright WILEY-VCH Verlag GmbH \& Co. KGaA, 69469 Weinheim, Germany, 2018.

\section{Supporting Information}

\section{Unravelling Photocatalytic Mechanism and Selectivity in PET-RAFT Polymerization}

Prasenjit Seal, * Jiangtao Xu, Sergio De Luca, Cyrille Boyer, and Sean C. Smith*

\section{Contents}

1. Chemical drawing of all the species involved

2. Naming convention of the catalyst-RAFT agent complexes

3. Detailed energy analysis of the PheoA-RAFT agent complexes studied in the present work

4. The two faces, F1 and F2, of the photoredox catalyst, pheophorbide $a$ (PheoA)

5. The top and side-view of the first excited state M05/6-31G(d) + D3 optimized geometries for two representative complexes formed between the catalysts, PheoA and ZnTPP with the RAFT agents, CPADB and BTPA

6. Molecular orbitals for the catalyst-RAFT agent complexes, the catalyst, and the RAFT agents

7. Detailed orbital energy analysis (in eV) of PheoA-dithiobenzoate complexes in the triplet state and for all the PheoA-RAFT complexes in DMSO phase

8. Experiment section. 

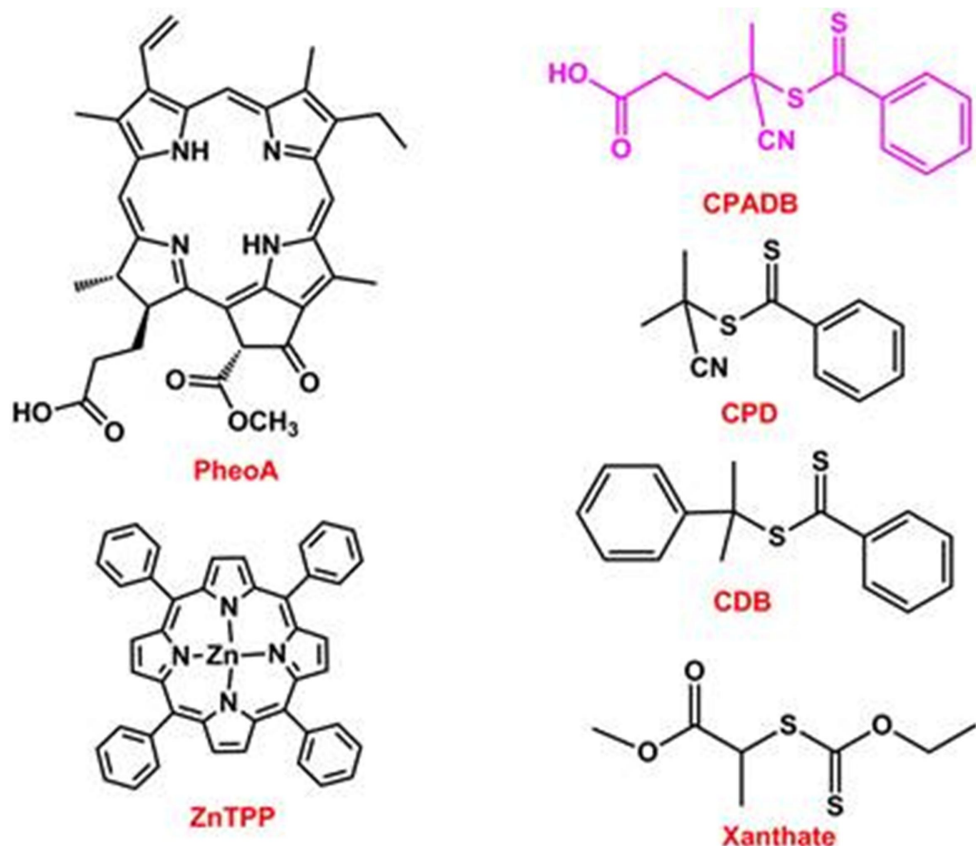

WILEY-VCH

Figure S1. Chemical drawings of the catalyst, PheoA and ZnTPP and the six RAFT agents considered in the present work. 
Table S1. The naming convention for the catalysts and the RAFT agents followed in the present work.

\begin{tabular}{|c|c|c|}
\hline $\mathrm{P}_{\text {RAFT agents }}^{\text {Catalyst }}$ & PheoA: $\mathrm{PC}_{1}$ & ZnTPP: $\mathrm{PC}_{2}$ \\
\hline CPADB: $\mathrm{RA}_{1}$ & $\mathrm{PC}_{1}-\mathrm{RA}_{1}$ & $\mathrm{PC}_{2}-\mathrm{RA}_{1}$ \\
\hline CPD: $\mathrm{RA}_{2}$ & $\mathrm{PC}_{1}-\mathrm{RA}_{2}$ & $\mathrm{PC}_{2}-\mathrm{RA}_{2}$ \\
\hline CDB: $\mathrm{RA}_{3}$ & $\mathrm{PC}_{1}-\mathrm{RA}_{3}$ & $\mathrm{PC}_{2}-\mathrm{RA}_{3}$ \\
\hline Xanthate: $\mathrm{RA}_{4}$ & $\mathrm{PC}_{1}-\mathrm{RA}_{4}$ & $\mathrm{PC}_{2}-\mathrm{RA}_{4}$ \\
\hline BSTP: $\mathrm{RA}_{5}$ & $\mathrm{PC}_{1}-\mathrm{RA}_{5}$ & $\mathrm{PC}_{2}-\mathrm{RA}_{5}$ \\
\hline BTPA: $\mathrm{RA}_{6}$ & $\mathrm{PC}_{1}-\mathrm{RA}_{6}$ & $\mathrm{PC}_{2}-\mathrm{RA}_{6}$ \\
\hline CPADB-MMA: $\mathrm{RA}_{1 \mathrm{p}}$ & $\mathrm{PC}_{1}-\mathrm{RA}_{1 \mathrm{p}}$ & _ \\
\hline CPD-MMA: $\mathrm{RA}_{2 \mathrm{p}}$ & $\mathrm{PC}_{1}-\mathrm{RA}_{2 \mathrm{p}}$ & - \\
\hline CDB-MMA: $\mathrm{RA}_{3 \mathrm{p}}$ & $\mathrm{PC}_{1}-\mathrm{RA}_{3 \mathrm{p}}$ & - \\
\hline CPADB-(MMA) $)_{2}: \mathrm{RA}_{1 \mathrm{pp}}$ & $\mathrm{PC}_{1}-\mathrm{RA}_{1 \mathrm{pp}}$ & - \\
\hline $\mathrm{CPD}-(\mathrm{MMA})_{2}: \mathrm{RA}_{2 \mathrm{pp}}$ & $\mathrm{PC}_{1}-\mathrm{RA}_{2 \mathrm{pp}}$ & - \\
\hline $\mathrm{CDB}-(\mathrm{MMA})_{2}: \mathrm{RA}_{3 \mathrm{pp}}$ & $\mathrm{PC}_{1}-\mathrm{RA}_{3 \mathrm{pp}}$ & - \\
\hline
\end{tabular}




\section{WILEY-VCH}

Table S2. Detailed energy analysis of the PheoA-RAFT agent complexes studied in the present work. 23

\begin{tabular}{|c|c|c|c|c|c|c|c|c|c|c|c|c|}
\hline 24tomplexes & & & & & -phase & & & & & & DMSO & \\
\hline $\begin{array}{l}20 \\
26\end{array}$ & & surface $1(F 1$ & & & surface 2 & & $E_{\mathrm{DFT}+\mathrm{D} 3}^{\mathrm{F} 1}$ & Binding & ergies & $E_{\mathrm{DFT}+\mathrm{D} 3}^{\mathrm{F} 1}$ & $E_{\mathrm{DFT}+\mathrm{D} 3}^{\mathrm{F} 2}$ & $E_{\mathrm{DFT}+\mathrm{D} 3}^{\mathrm{F} 1}-$ \\
\hline $\begin{array}{r}28 \\
29 \\
30\end{array}$ & $E_{\mathrm{DFT}+\mathrm{D} 3}$ (a.u.) & $E_{\mathrm{DFT}}$ (a.u.) & $\begin{array}{c}E_{\text {disp }} \\
(\mathrm{kcal} / \mathrm{mol})\end{array}$ & $\begin{array}{c}E_{\mathrm{DFT}+\mathrm{D} 3} \\
\text { (a.u.) }\end{array}$ & $\begin{array}{l}E_{\mathrm{DFT}} \\
\text { (a.u.) }\end{array}$ & $\begin{array}{c}E_{\mathrm{disp}} \\
(\mathrm{kcal} / \mathrm{mol})\end{array}$ & $(\mathrm{kcal} / \mathrm{mol})$ & $B E_{\mathrm{F} 1}$ & $B E_{\mathrm{F} 2}$ & & & $(\mathrm{kcal} / \mathrm{mol})$ \\
\hline $31 \mathrm{PC}_{1}-\mathrm{RA}_{1}$ & -3453.669 & -3453.588 & -50.828 & -3453.664 & -3453.581 & -52.083 & -3.070 & -28.29 & -25.22 & -3453.699 & -3453.696 & -1.507 \\
\hline $32 \mathrm{PC}_{1}-\mathrm{RA}_{2}$ & -3225.880 & -3225.809 & -44.553 & -3225.874 & -3225.807 & -42.043 & -3.388 & -20.52 & -17.13 & -3225.905 & -3225.905 & -0.235 \\
\hline $33 \mathrm{PC}_{1}-\mathrm{RA}_{3}$ & -3364.564 & -3364.487 & -48.318 & -3364.567 & -3364.491 & -47.691 & 2.413 & -19.78 & -22.19 & -3364.593 & -3364.595 & 1.595 \\
\hline $34 \mathrm{PC}_{1}-\mathrm{RA}_{4}$ & -3245.070 & -3245.001 & -43.298 & -3245.076 & -3245.005 & -44.553 & 3.641 & -19.79 & -23.43 & -3245.099 & -3245.103 & 2.510 \\
\hline $35 \mathrm{PC}_{1}-\mathrm{RA}_{5}$ & -3720.403 & -3720.322 & -50.828 & -3720.399 & -3720.325 & -46.436 & -2.588 & -31.51 & -28.92 & -3720.423 & -3720.428 & 3.078 \\
\hline $\begin{array}{l}36 \mathrm{PC}_{1}-\mathrm{RA}_{6} \\
37\end{array}$ & -3607.367 & -3607.296 & -44.553 & -3607.374 & -3607.290 & -52.711 & 4.093 & -26.58 & -30.67 & -3607.387 & -3607.395 & 5.005 \\
\hline
\end{tabular}

37

$E_{\mathrm{disp}}=E_{\mathrm{DFT}+\mathrm{D} 3}-E_{\mathrm{DFT}}$

$B E_{\mathrm{F} 1}=E_{\mathrm{F} 1}-E_{\mathrm{PC} 1}-\mathrm{E}_{\mathrm{RA} 1 / 2 / 3 / 4 / 5 / 6}$

$B E_{\mathrm{F} 2}=E_{\mathrm{F} 2}-E_{\mathrm{PC} 1}-\mathrm{E}_{\mathrm{RA} 1 / 2 / 3 / 4 / 5 / 6}$ 

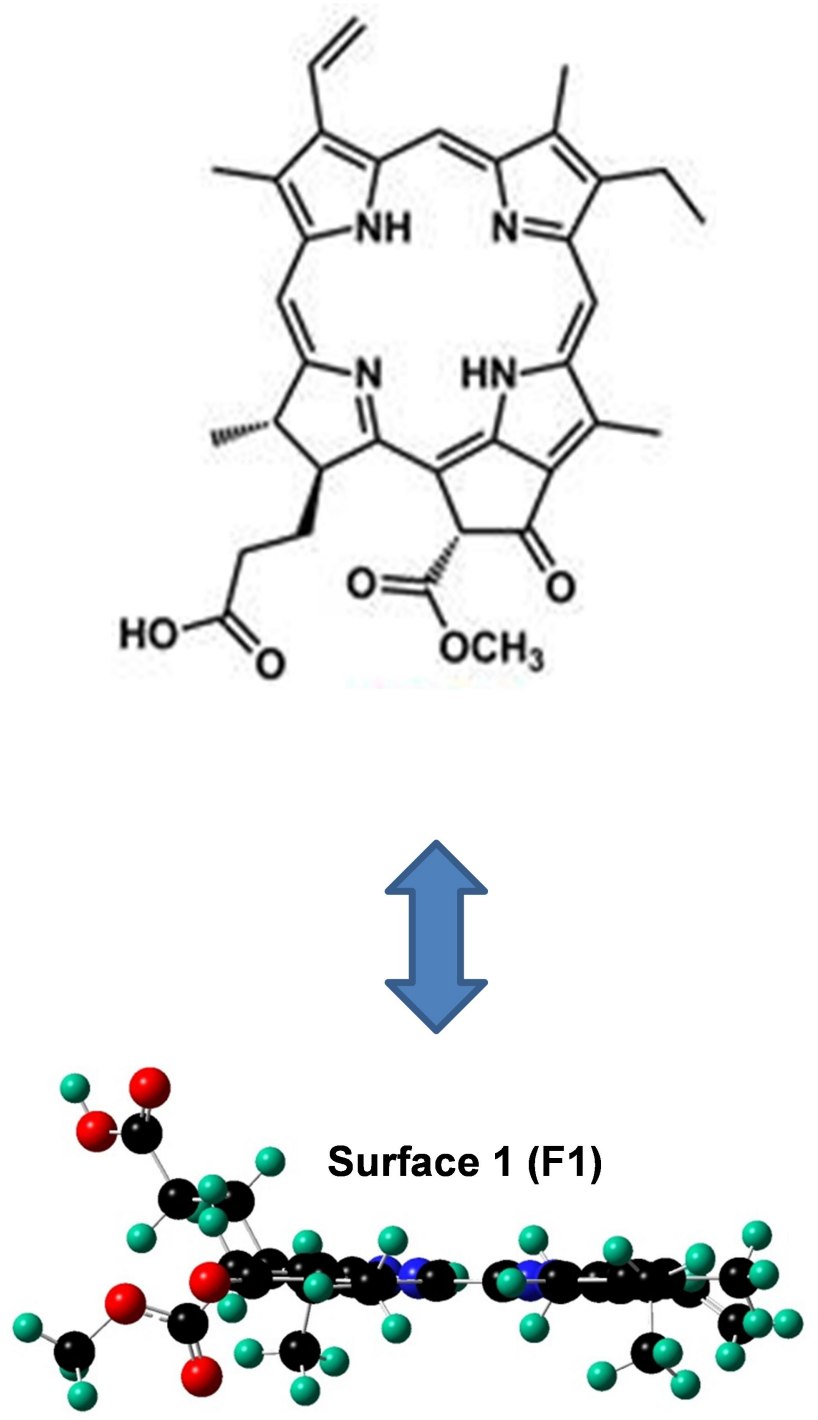

Surface 2 (F2)

Figure S2. The two surfaces, F1 and F2, of the photoredox catalyst, pheophorbide $a$ (PheoA). 


\section{WILEY-VCH}

Top View

Side View

PheoA-CPADB

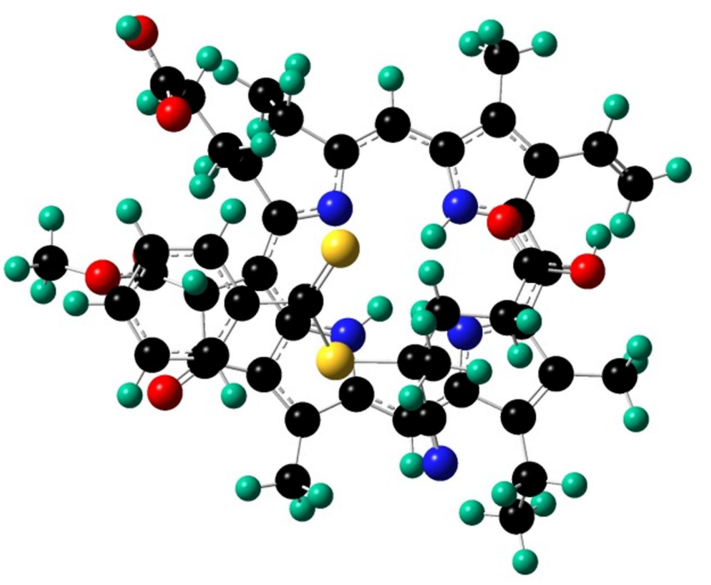

(a)

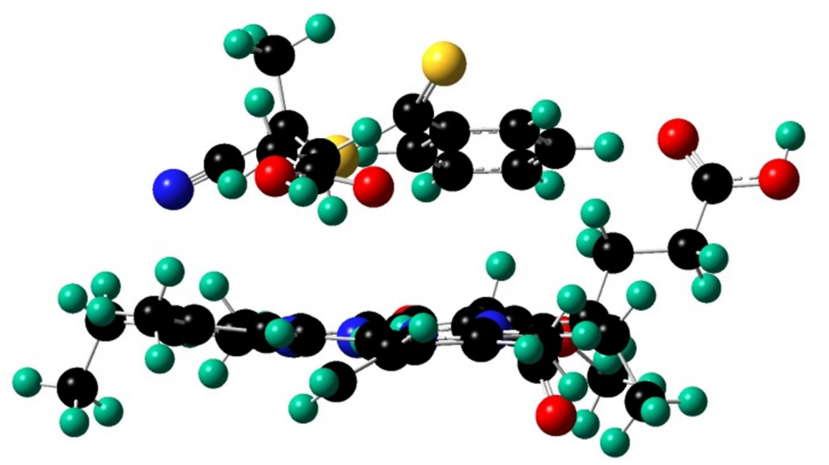

(b)

PheoA-BTPA

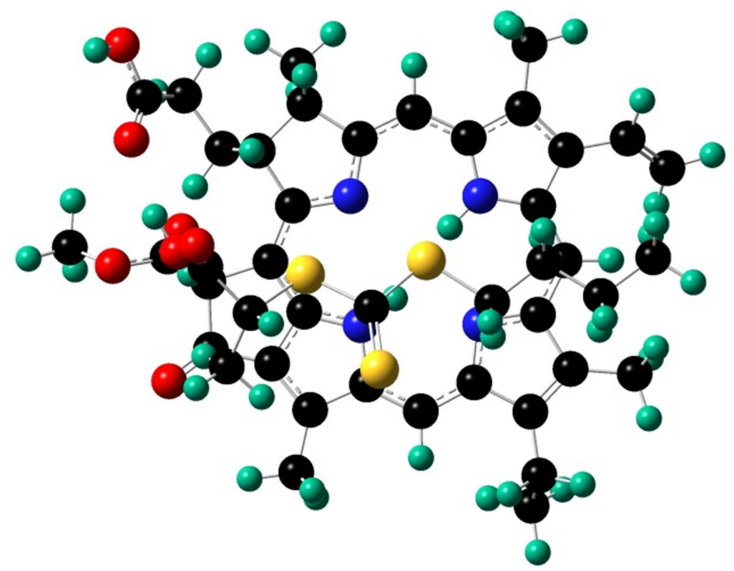

(c)

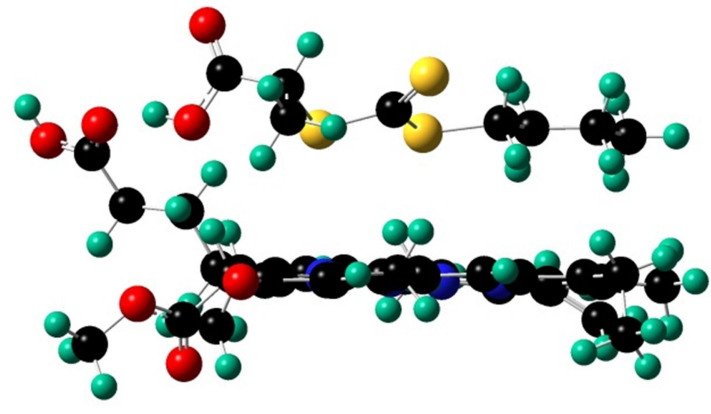

(d) 
Top View

Side View

\section{ZnTPP-CPADB}
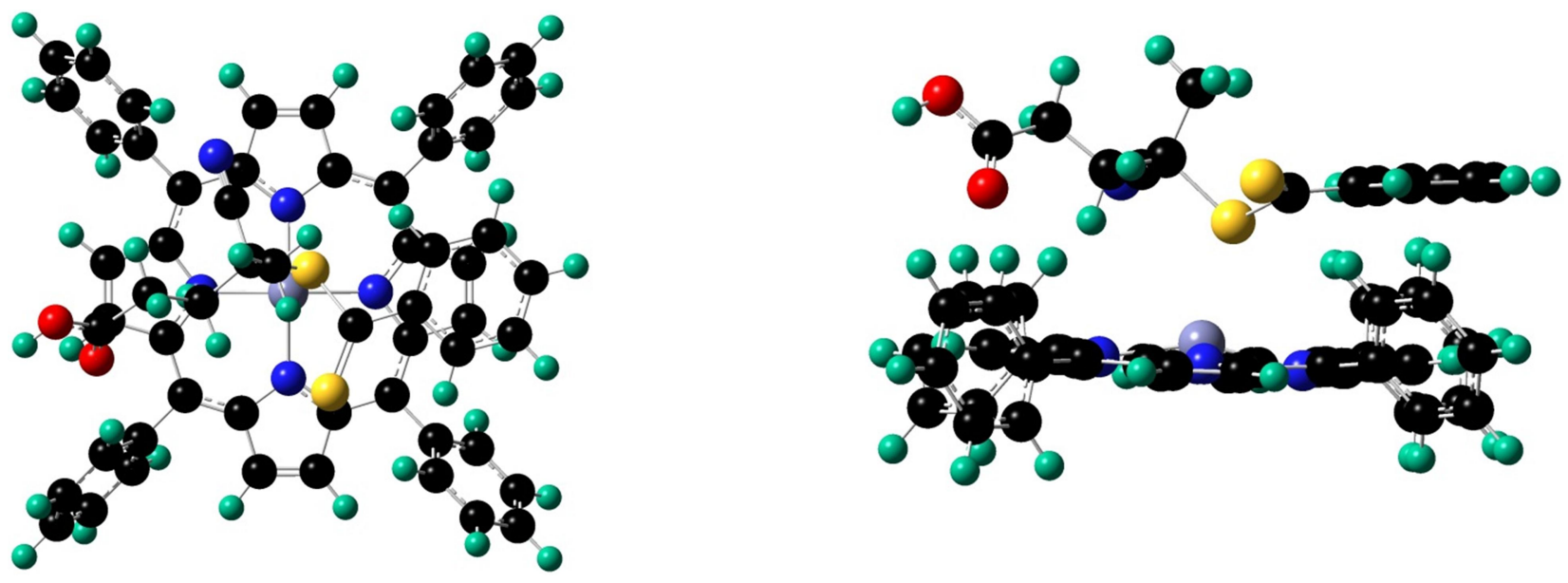

(e)

(f)

\section{ZnTPP-BTPA}
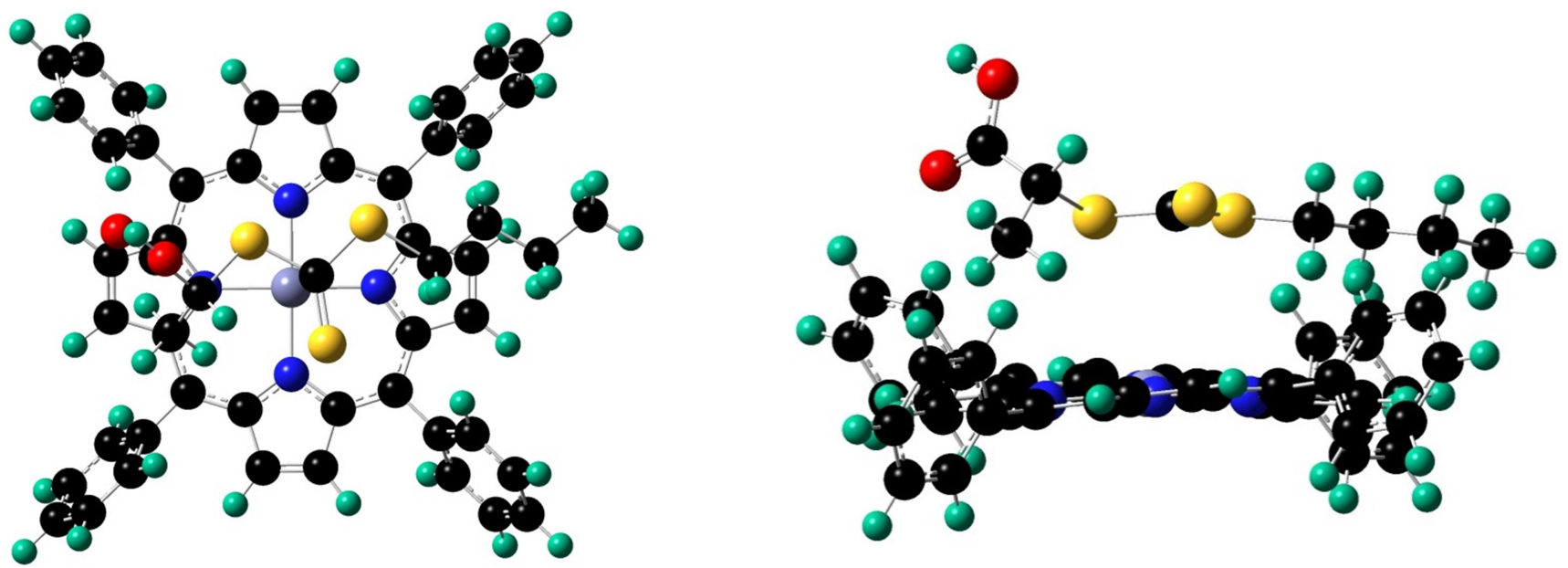

(g)

(h)

Figure S3. The M05/6-31G(d) + D3 optimized geometries of the first excited state for a representative set of four complexes formed between the catalysts, PheoA and ZnTPP with the RAFT agents, CPADB and BTPA: (a) PheoA-CPADB (top view), (b) PheoA-CPADB (side view), (c) PheoA-BTPA (top view), (d) PheoA-BTPA (side view), (e) ZnTPP-CPADB (top view), (f) ZnTPP-CPADB (side view), (g) ZnTPP-BTPA (top view), (h) ZnTPP-BTPA (side view). 


\section{WILEY-VCH}

Complexes formed with PheoA $\left(\mathrm{PC}_{1}\right) / \mathrm{ZnTPP}\left(\mathrm{PC}_{2}\right)$ with dithiobenzoate $\left(\mathrm{RA}_{1}, \mathrm{RA}_{2}\right.$, and RA $)$ RAFT agents

Complex

$\mathbf{P C}_{1}-\mathbf{R A}_{1}$

$\mathbf{P C}_{2}-\mathbf{R A}_{1}$
HOMO

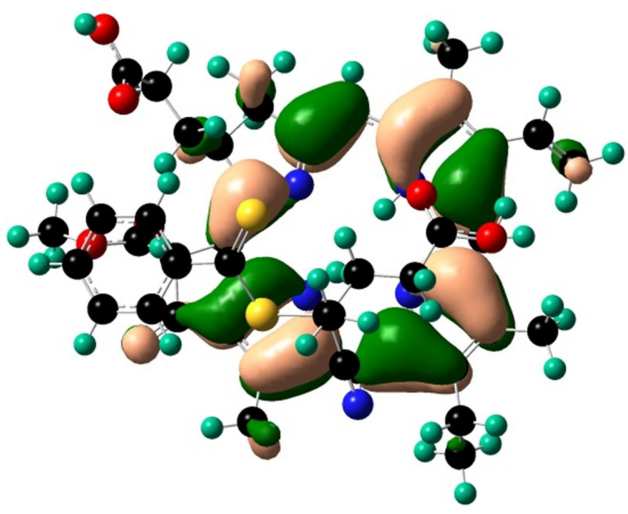

HOMO

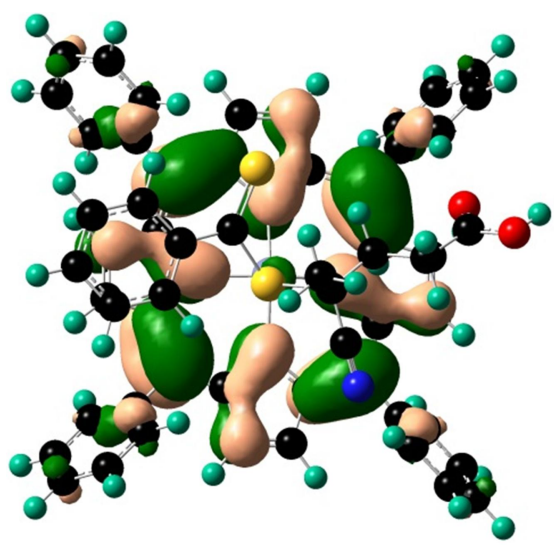

$$
\text { LUMO + } 1
$$

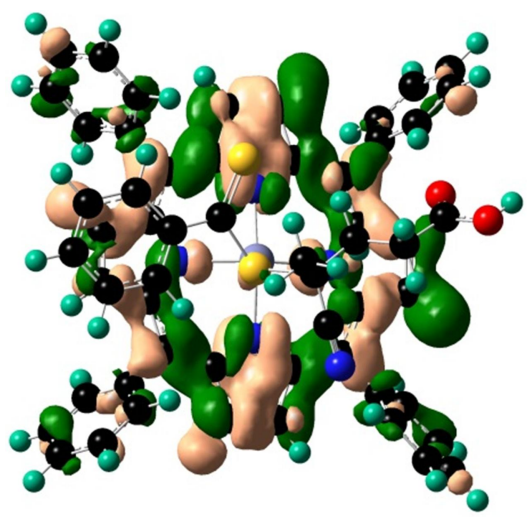

LUMO + 2

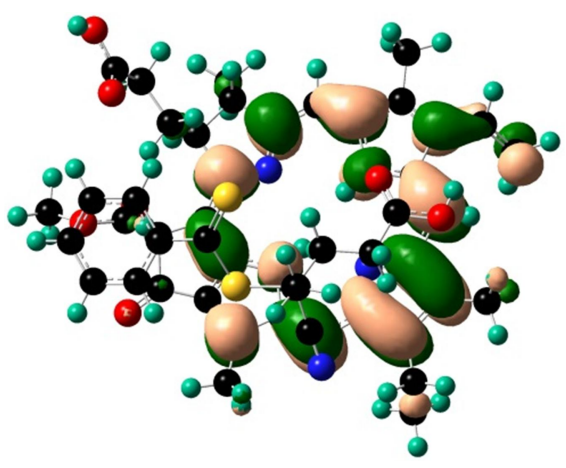

\section{LUMO}

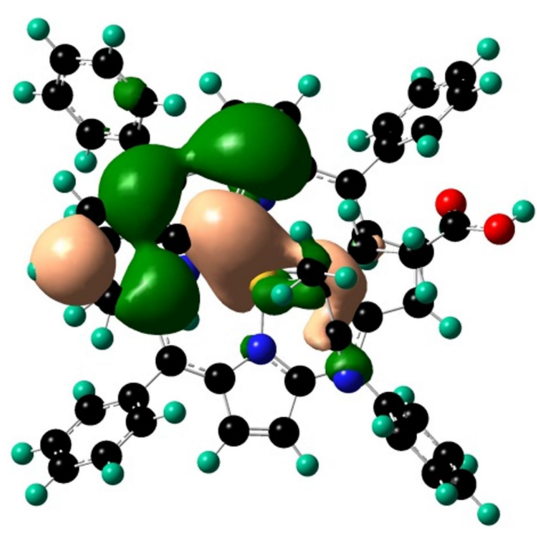

$$
\text { LUMO + } 2
$$

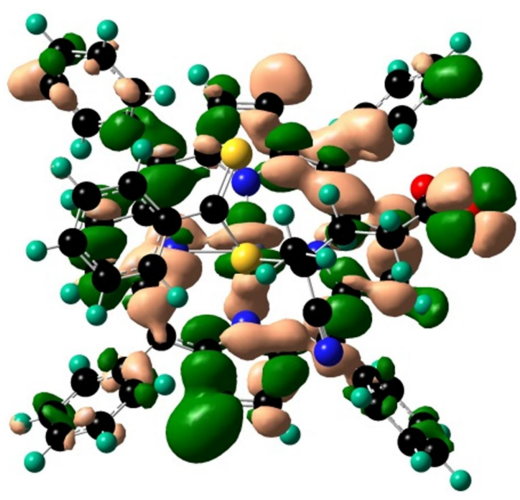




\section{WILEY-VCH}

HOMO

$\mathbf{P C}_{\mathbf{1}}-\mathbf{R A}_{\mathbf{2}}$

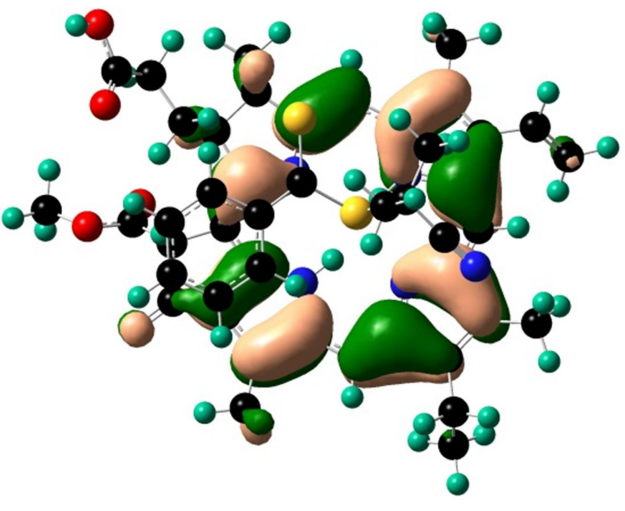

$$
\text { LUMO + } 1
$$

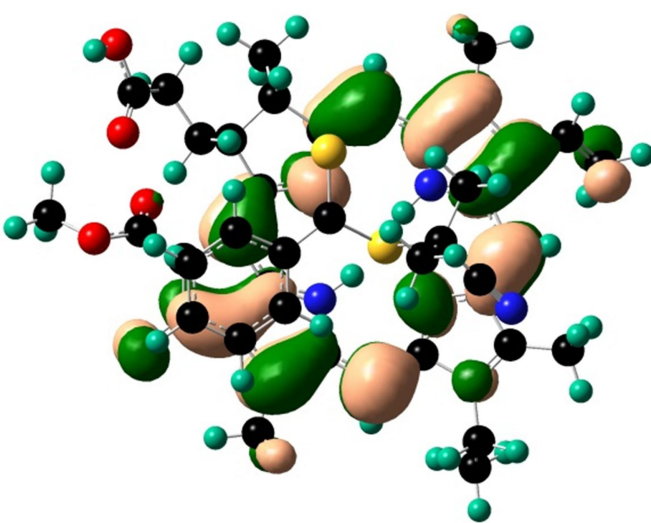

HOMO

$$
\mathbf{P C}_{2}-\mathbf{R A}_{2}
$$

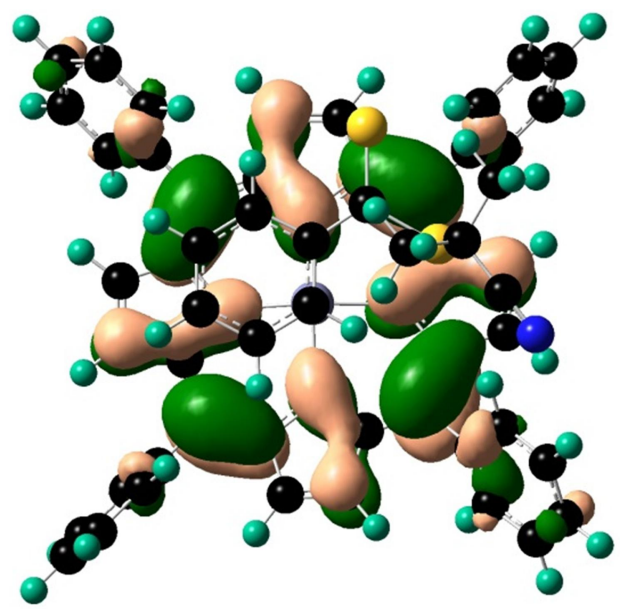

LUMO

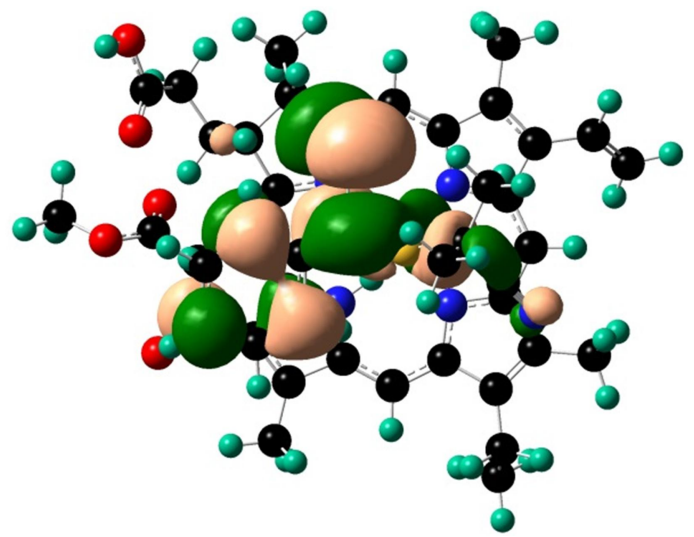

LUMO + 2

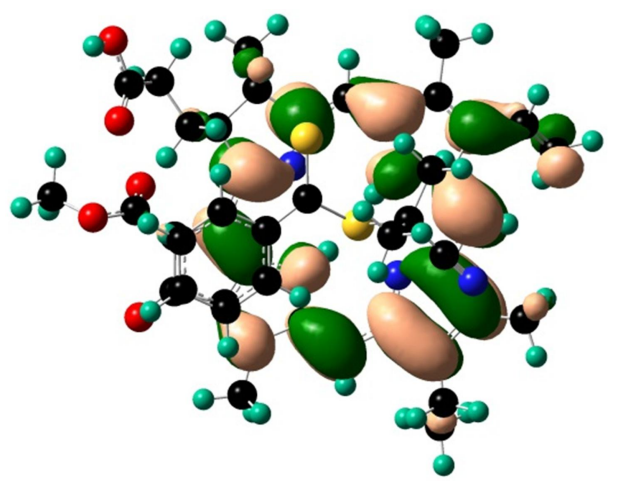

LUMO

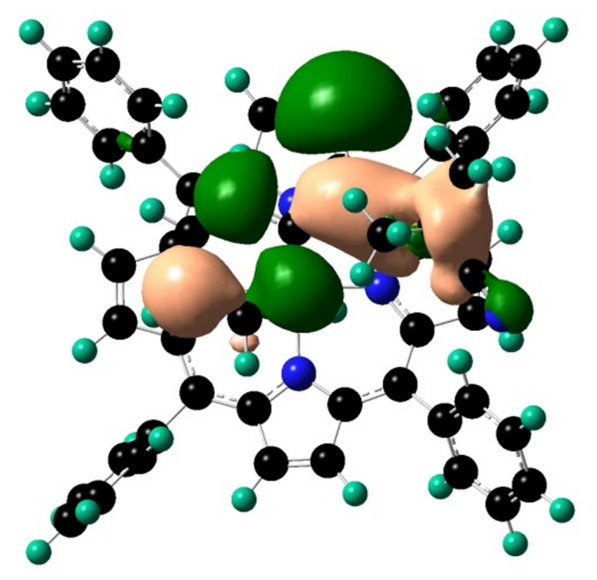


WILEY-VCH

LUMO + 1

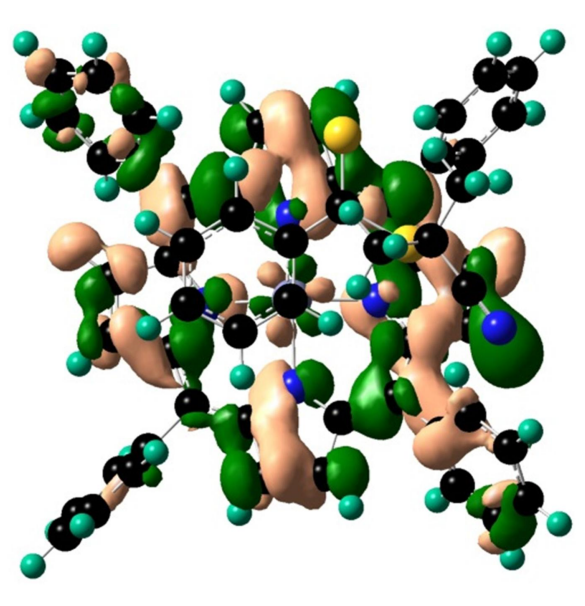

HOMO

$$
\mathbf{P C}_{1}-\mathbf{R A}_{3}
$$

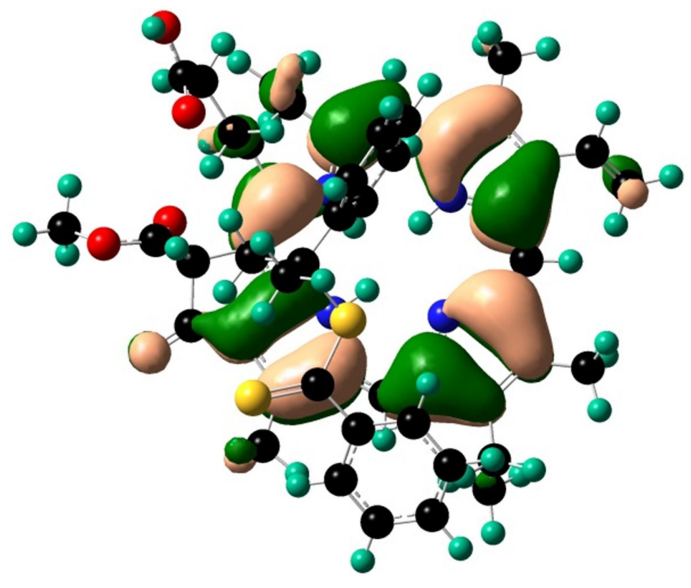

$$
\text { LUMO + } 1
$$

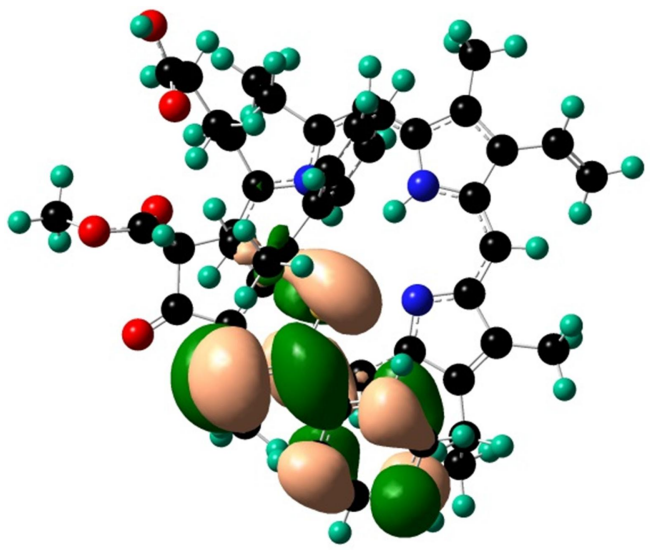

LUMO + 2

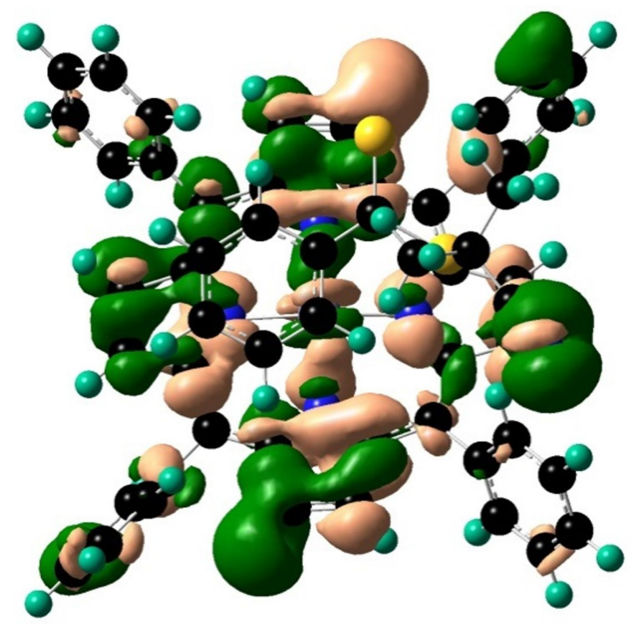

LUMO

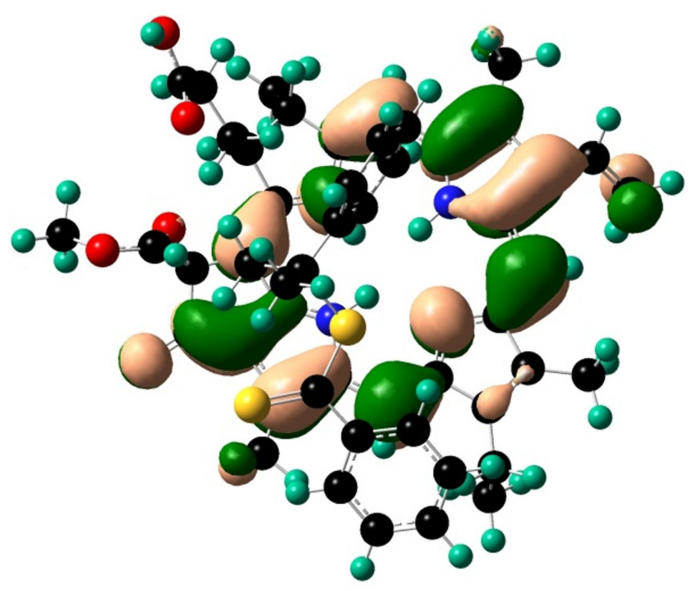

LUMO + 2

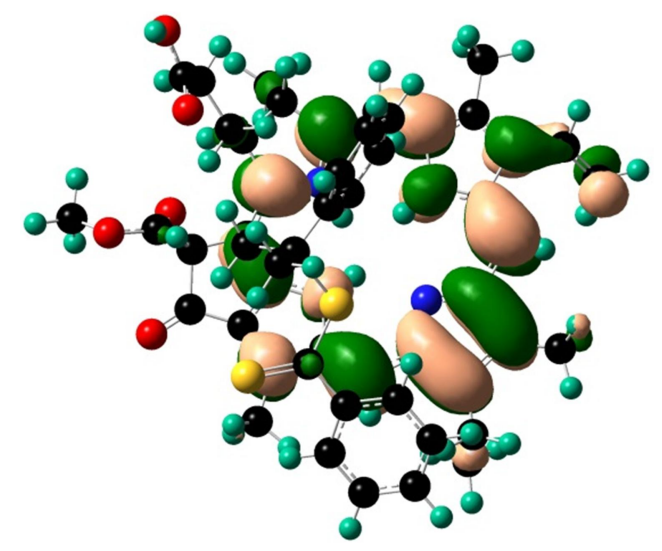




\section{WILEY-VCH}

HOMO

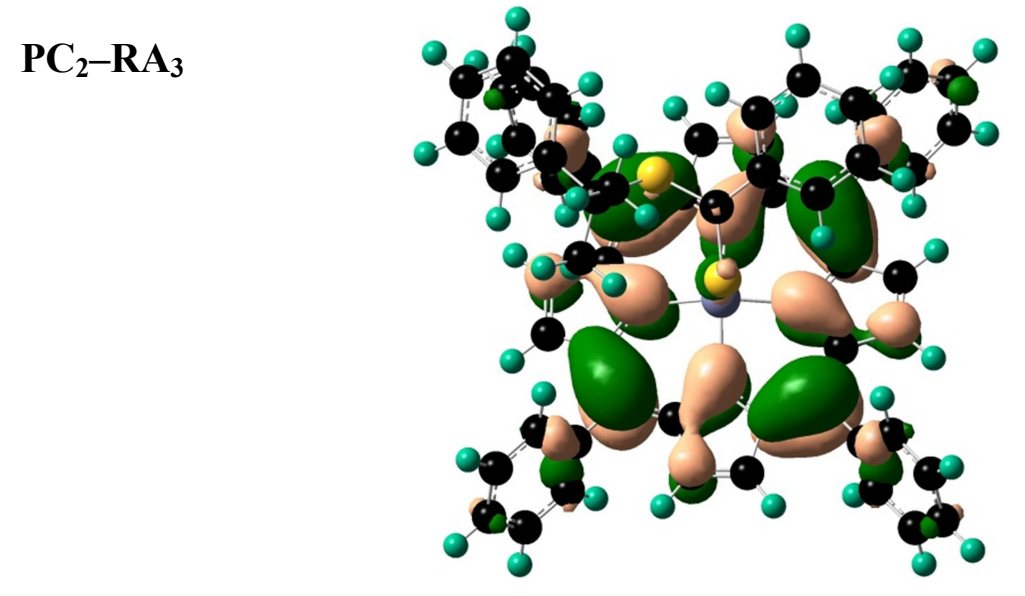

$$
\text { LUMO + } 1
$$

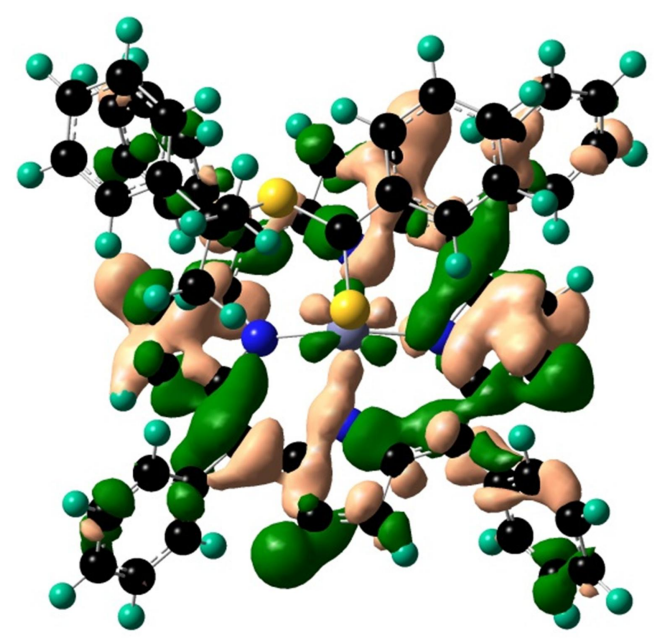

LUMO

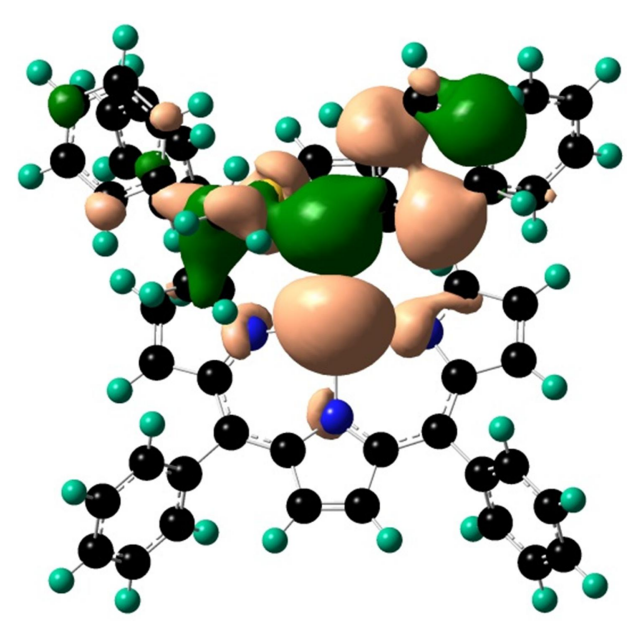

LUMO + 2

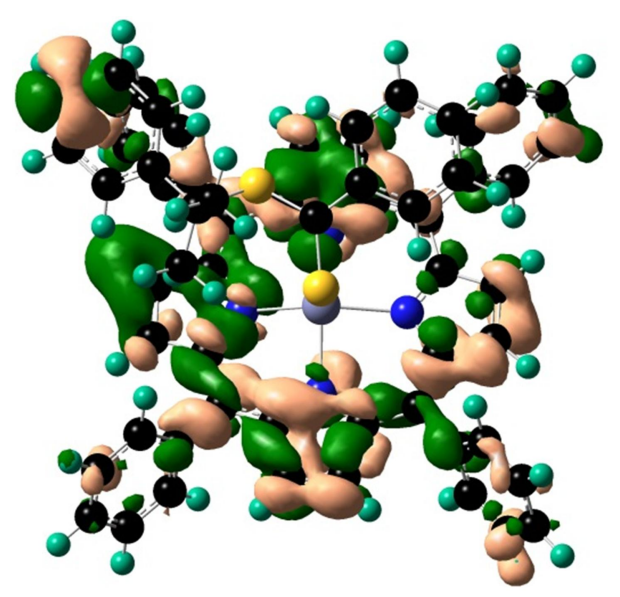




\section{WILEY-VCH}

Complexes formed with PheoA $\left(\mathrm{PC}_{1}\right) / \mathrm{ZnTPP}\left(\mathrm{PC}_{2}\right)$ with xanthate $\left(\mathrm{RA}_{4}\right)$ and trithiocarbonate $\left(\mathrm{RA}_{5}\right.$ and $\left.\mathrm{RA}_{6}\right) \mathrm{RAFT}$ agents

Complex

$\mathbf{P C}_{1}-\mathbf{R A}_{4}$

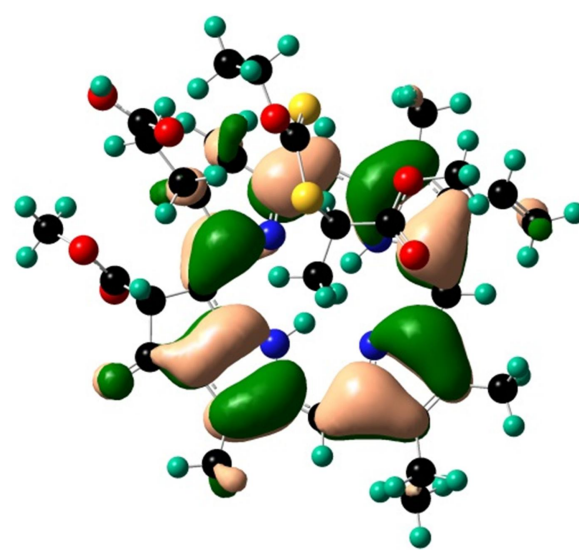

LUMO + 1

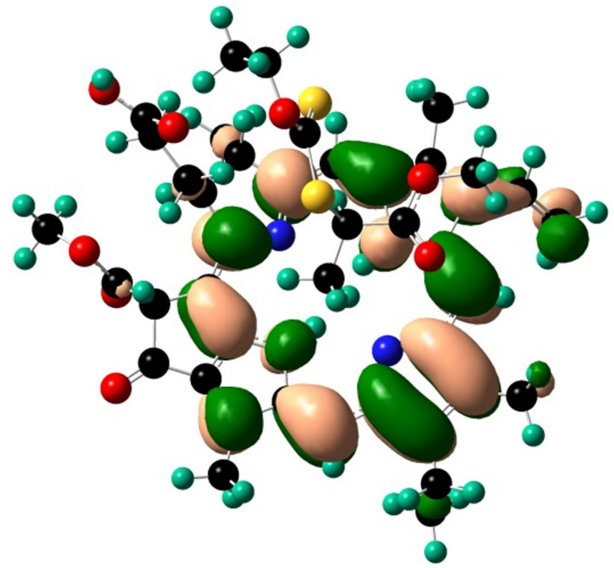

HOMO

$\mathbf{P C}_{2}-\mathbf{R A}_{4}$

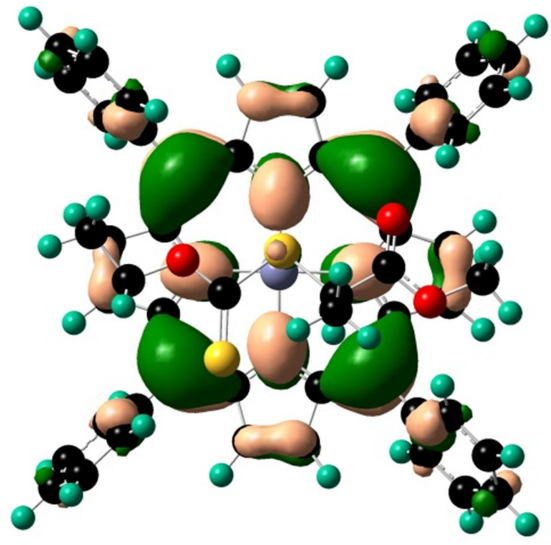

LUMO

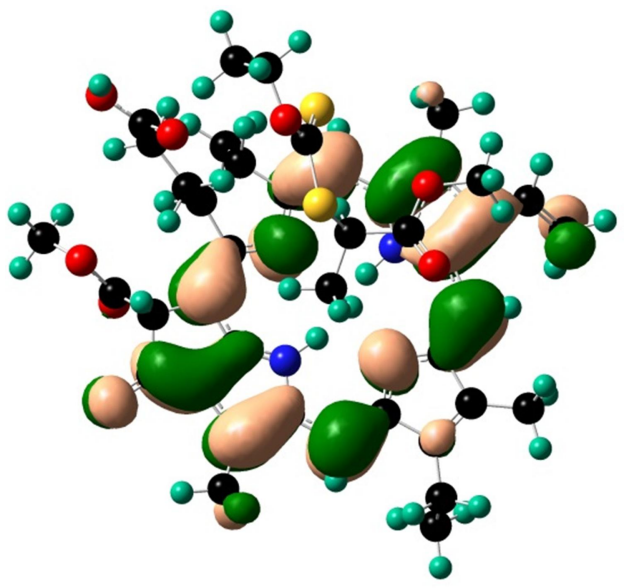

LUMO + 2

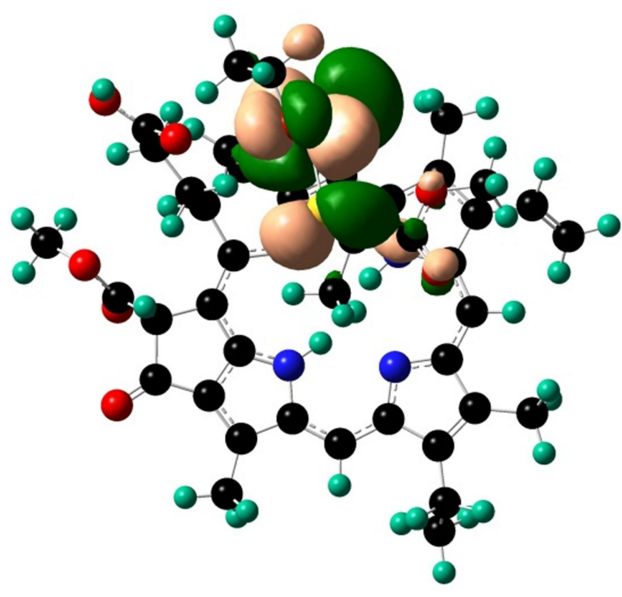

LUMO

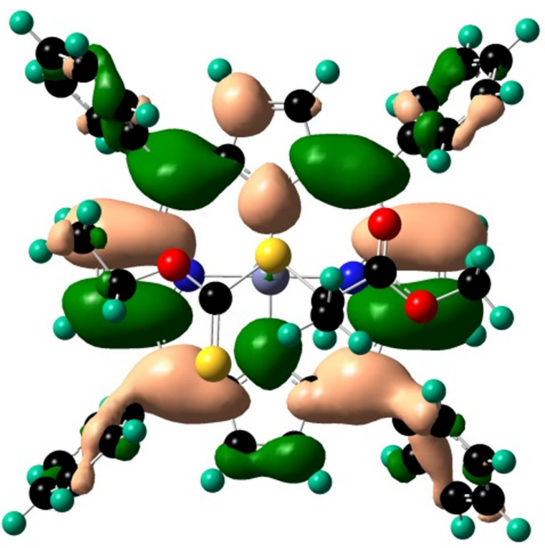


LUMO + 1

$\mathrm{PC}_{2}-\mathrm{RA}_{4}$

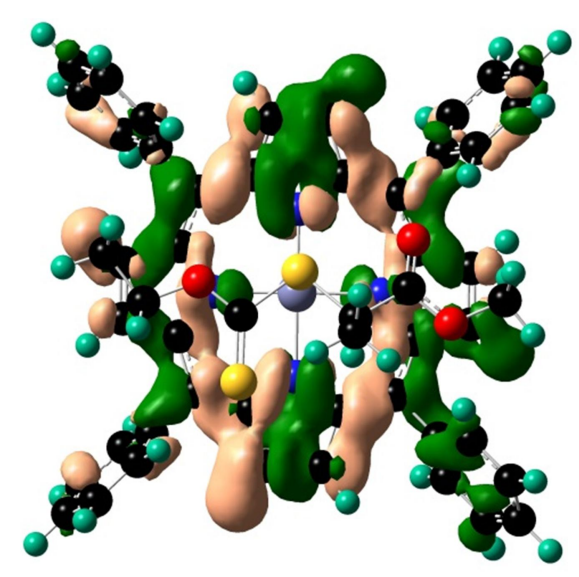

HOMO
LUMO + 2

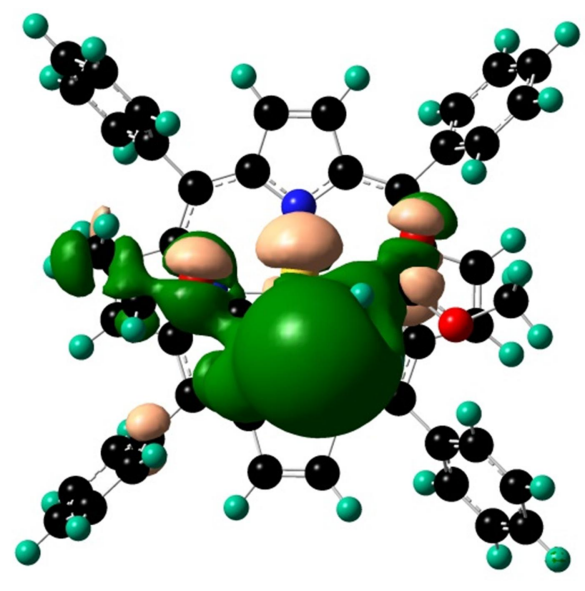

LUMO

$\mathrm{PC}_{1}-\mathrm{RA}_{5}$
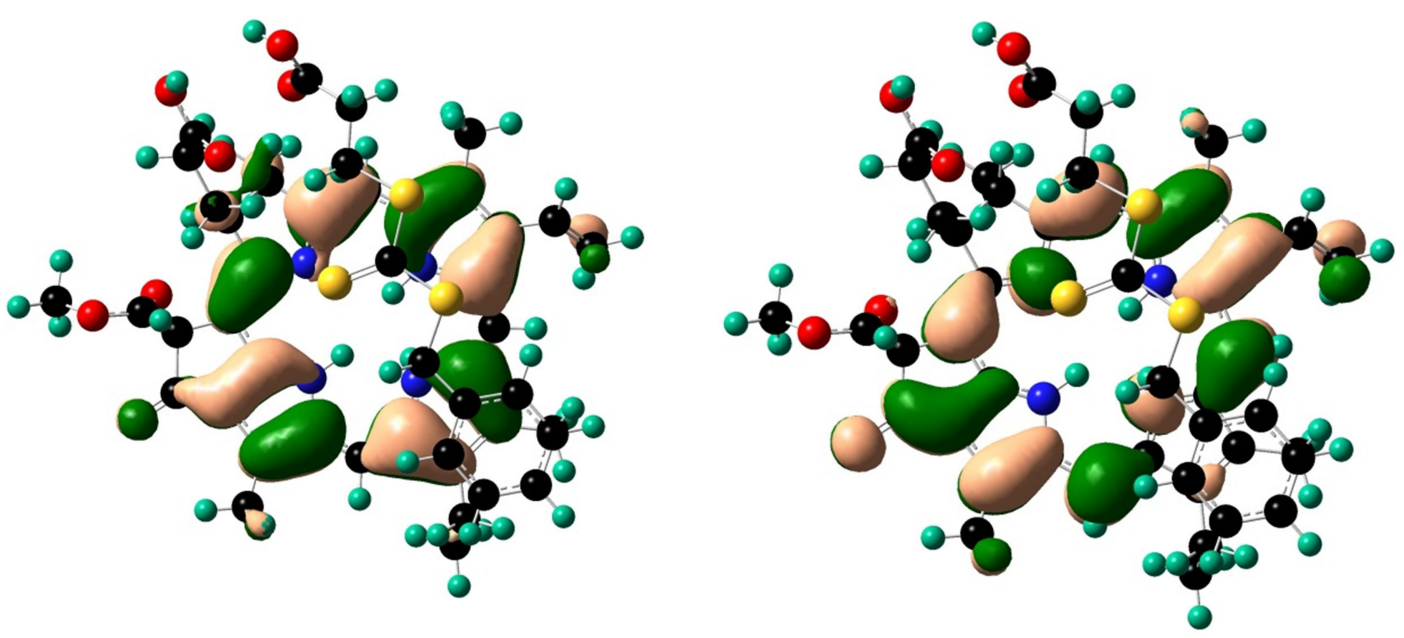

LUMO + 1

LUMO + 2
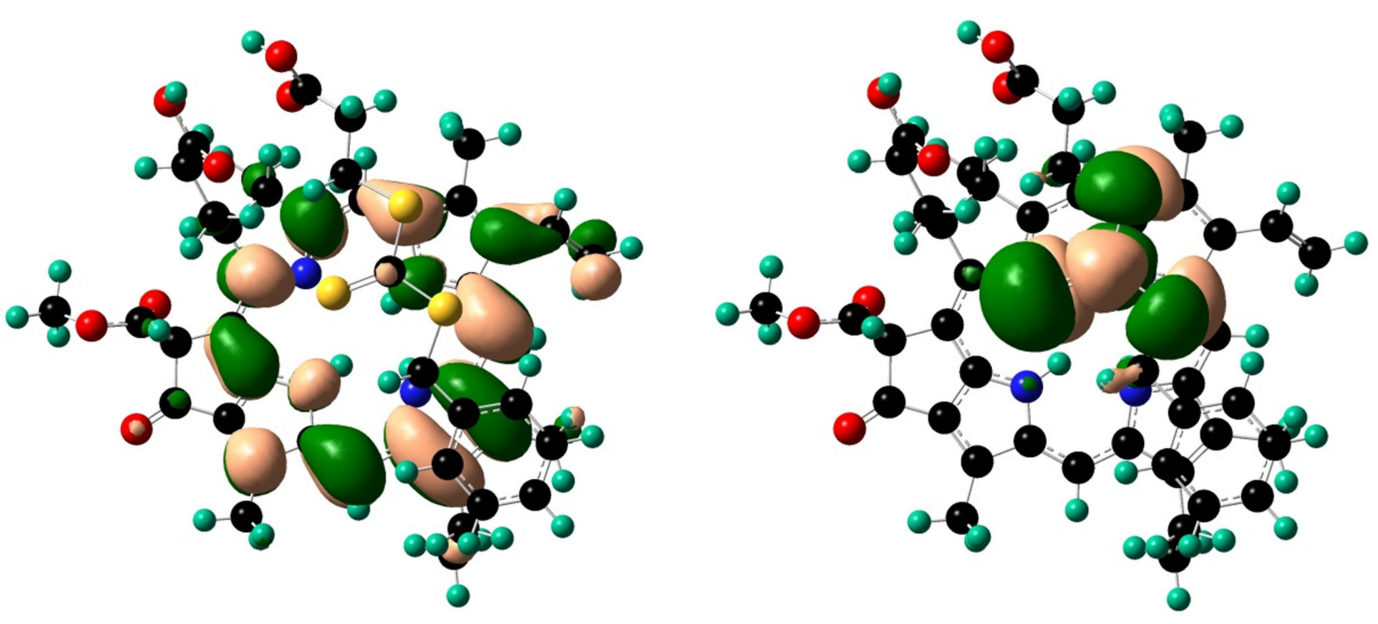


\section{WILEY-VCH}

HOMO

$\mathbf{P C}_{2}-\mathbf{R A}_{5}$
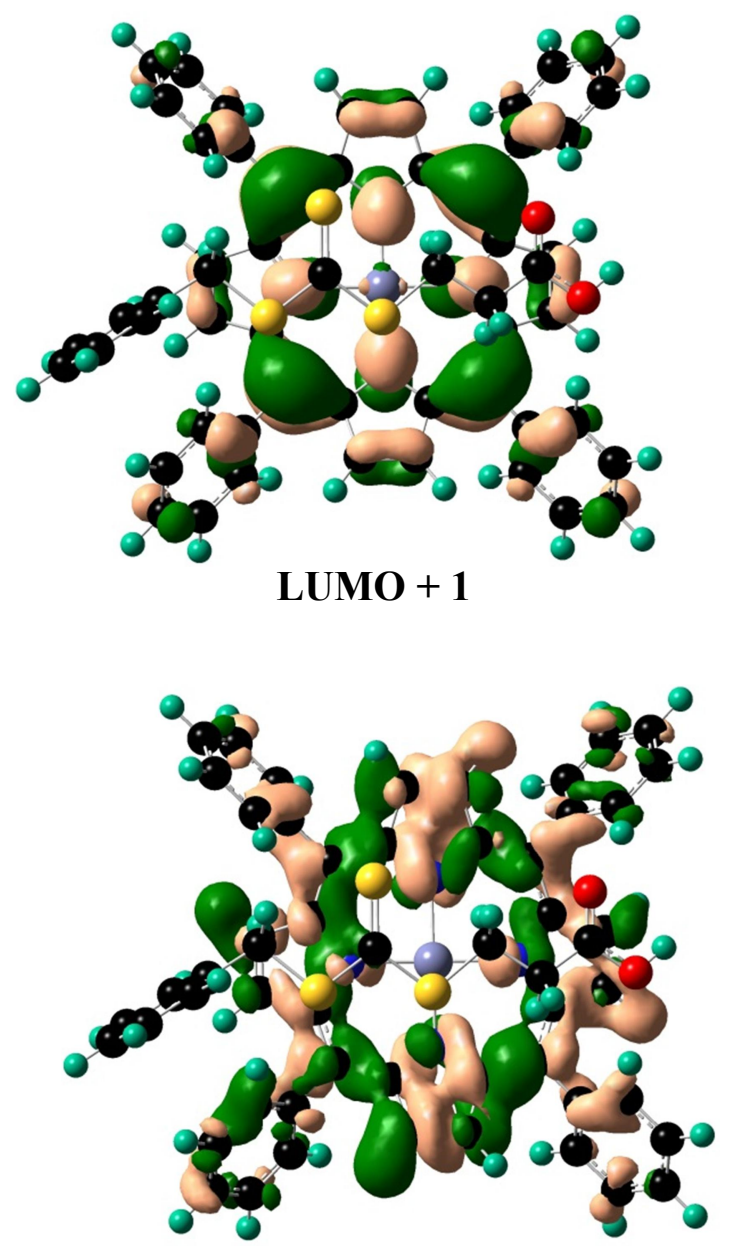

HOMO

$\mathbf{P C}_{1}-\mathbf{R A}_{6}$

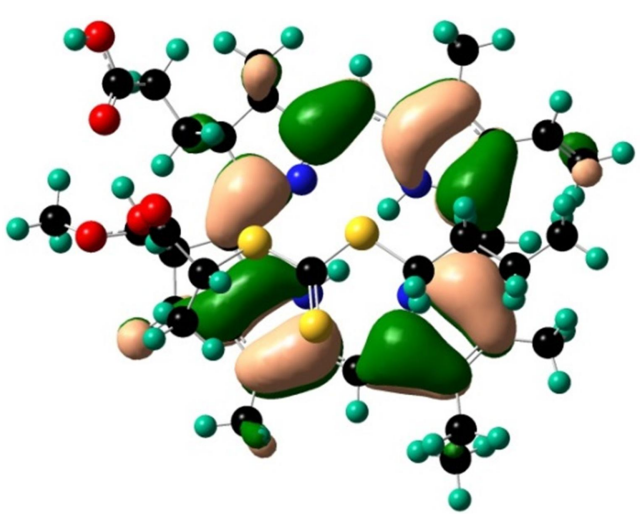

LUMO + 1

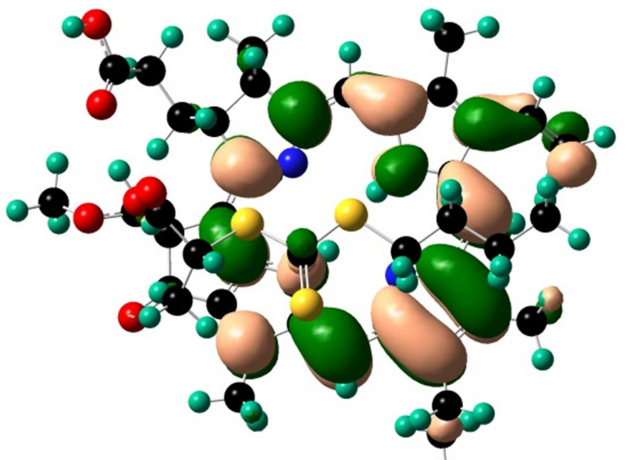

LUMO

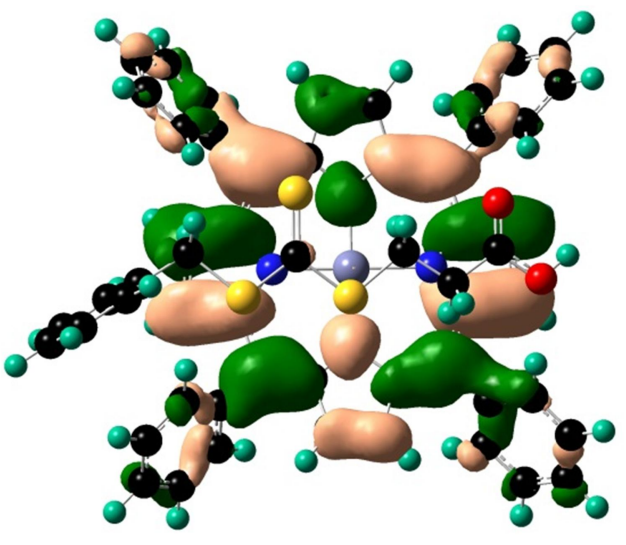

LUMO + 2

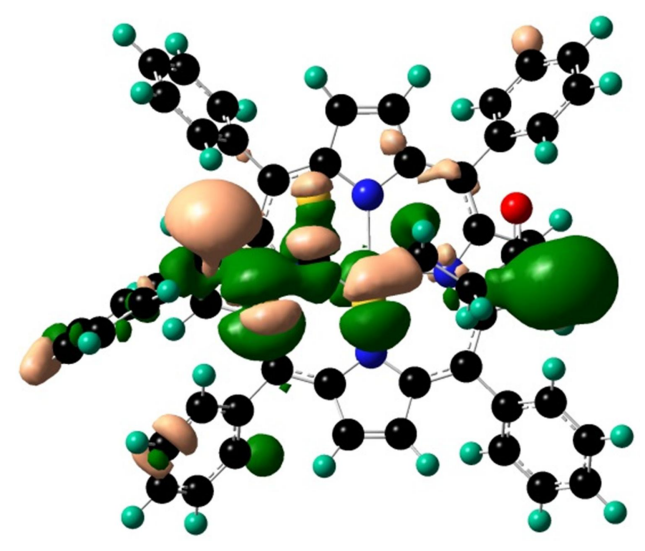

LUMO

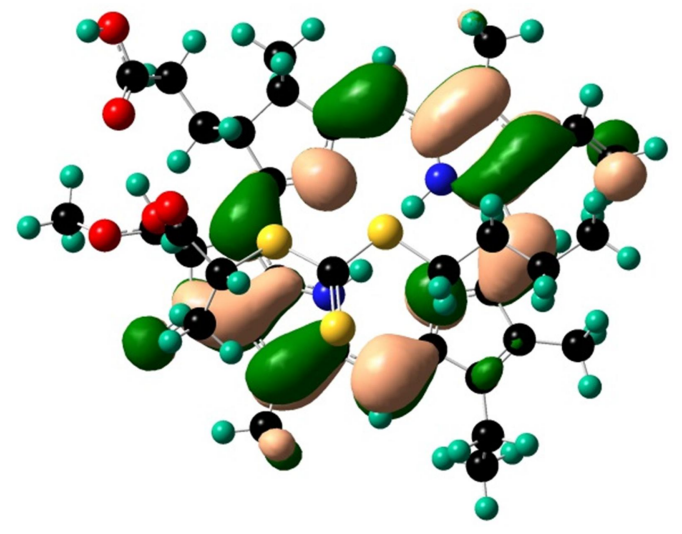

LUMO + 2

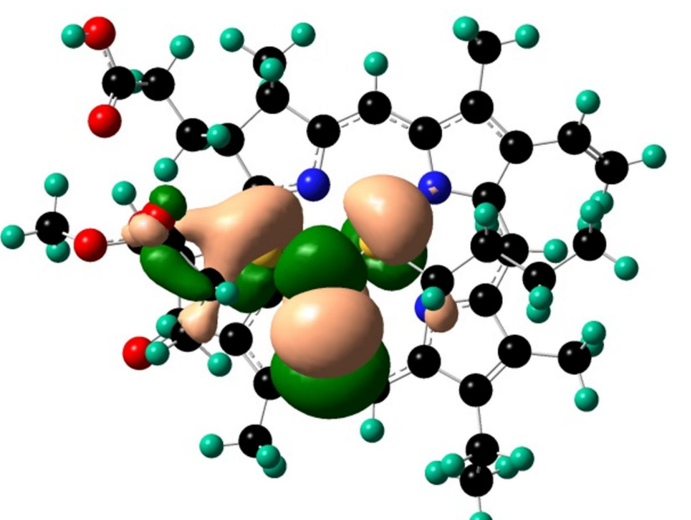


$\mathbf{P C}_{2}-\mathbf{R A}_{6}$
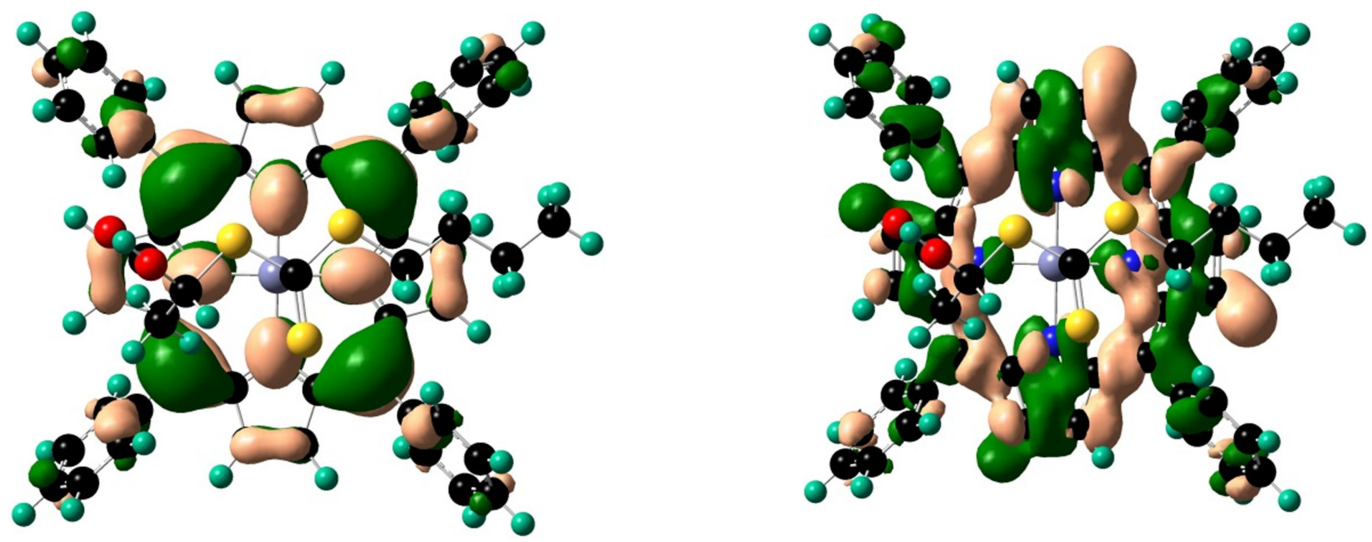

Figure S4. Detailed molecular orbital analyses for all the complexes under investigation at M05/6-31G(d) + D3 level of theory. The complexes formed by PheoA and ZnTPP with RAFT agents of dithiobenzoate moieties, i.e., PheoA/ZnTPP -CPD $\left(\mathrm{PC}_{1} / \mathrm{PC}_{2}-\mathrm{RA}_{2}\right)$ and PheoA/ZnTPP-CDB $\left(\mathrm{PC}_{1} / \mathrm{PC}_{2}-\mathrm{RA}_{3}\right)$ have their LUMO and LUMO +1 orbitals involved in the crucial transition whereas for the complexes that are formed by the catalysts with xanthate and trithiocarbonate RAFT agents, i.e., PheoA/ZnTPP-Xanthate $\left(\mathrm{PC}_{1} / \mathrm{PC}_{2}-\mathrm{RA}_{4}\right)$ and PheoA/ZnTPP -BSTP $\left(\mathrm{PC}_{1} / \mathrm{PC}_{2}-\mathrm{RA}_{5}\right)$, it is the LUMO and LUMO +2 orbitals those are involved. The orbitals that have the dominant contributions from the catalysts only are $\mathrm{HOMO}$ and $\mathrm{LUMO}+2: \mathrm{PC}_{1} / \mathrm{PC}_{2}-\mathrm{RA}_{1}, \mathrm{PC}_{1} / \mathrm{PC}_{2}-\mathrm{RA}_{2}$ and $\mathrm{PC}_{1} / \mathrm{PC}_{2}-\mathrm{RA}_{3} ; \mathrm{HOMO}$ and $\mathrm{LUMO}+1: \mathrm{PC}_{1} / \mathrm{PC}_{2}-\mathrm{RA}_{4}, \mathrm{PC}_{1} / \mathrm{PC}_{2}-\mathrm{RA}_{5}$, and $\mathrm{PC}_{1} / \mathrm{PC}_{2}-\mathrm{RA}_{6}$. 


\section{WILEY-VCH}

HOMO

LUMO

Catalyst, PheoA $\left(\mathrm{PC}_{1}\right)$
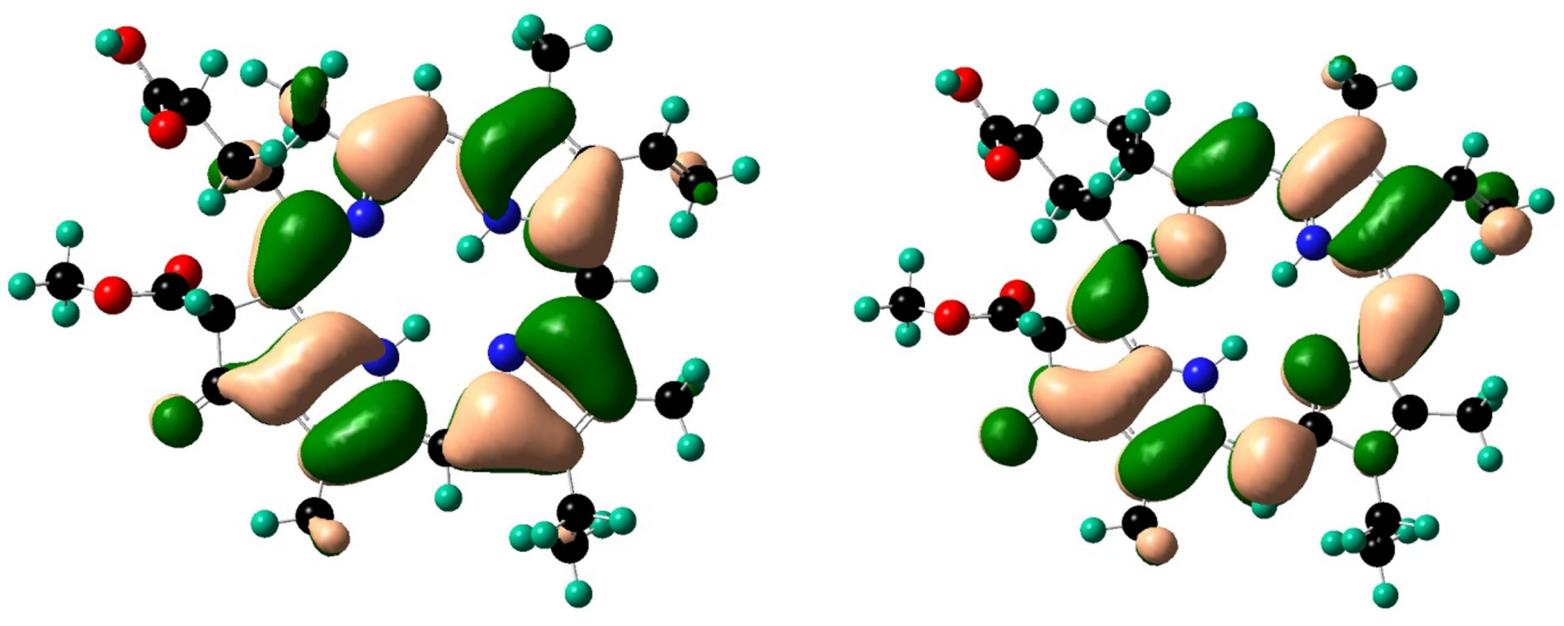

Catalyst, ZnTPP $\left(\mathrm{PC}_{2}\right)$
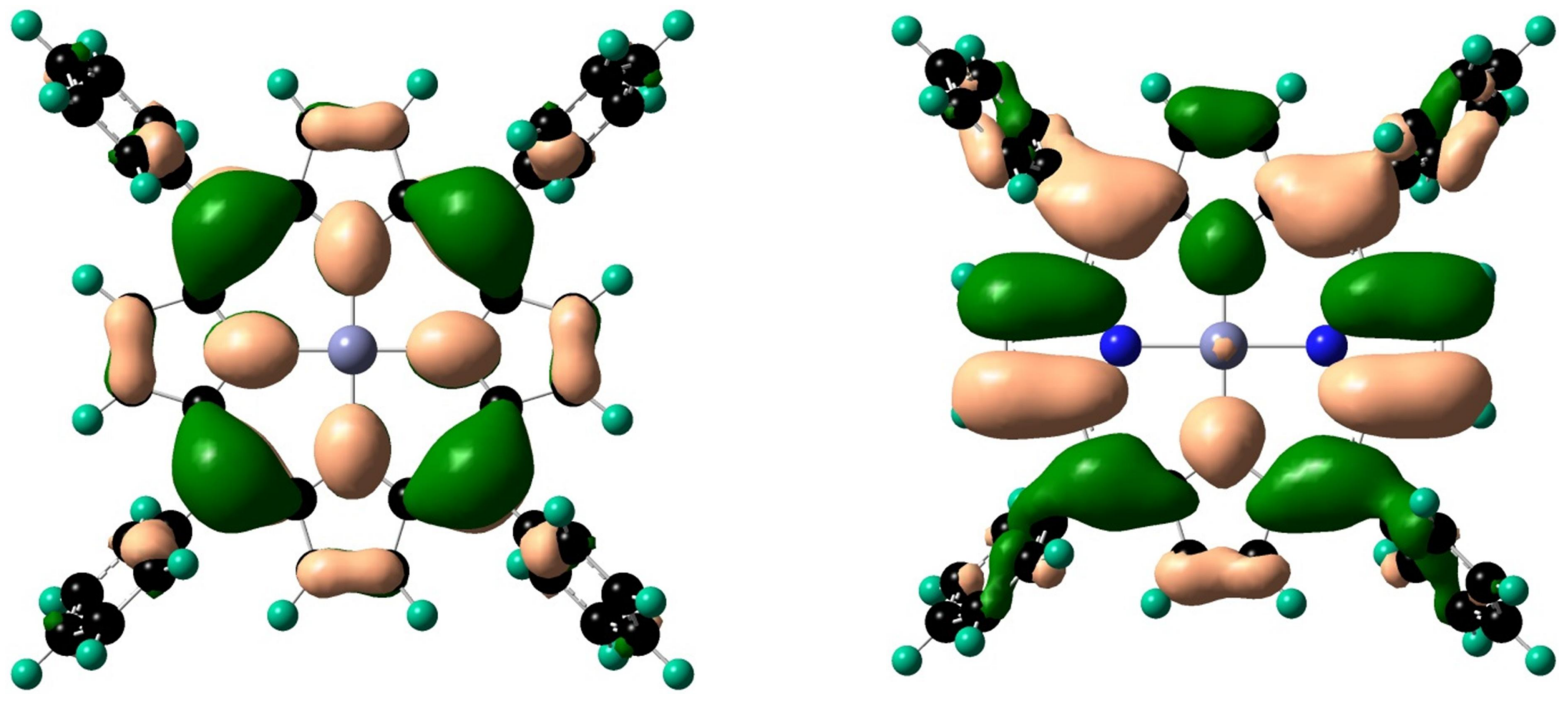

$$
\text { CPADB (RA })
$$
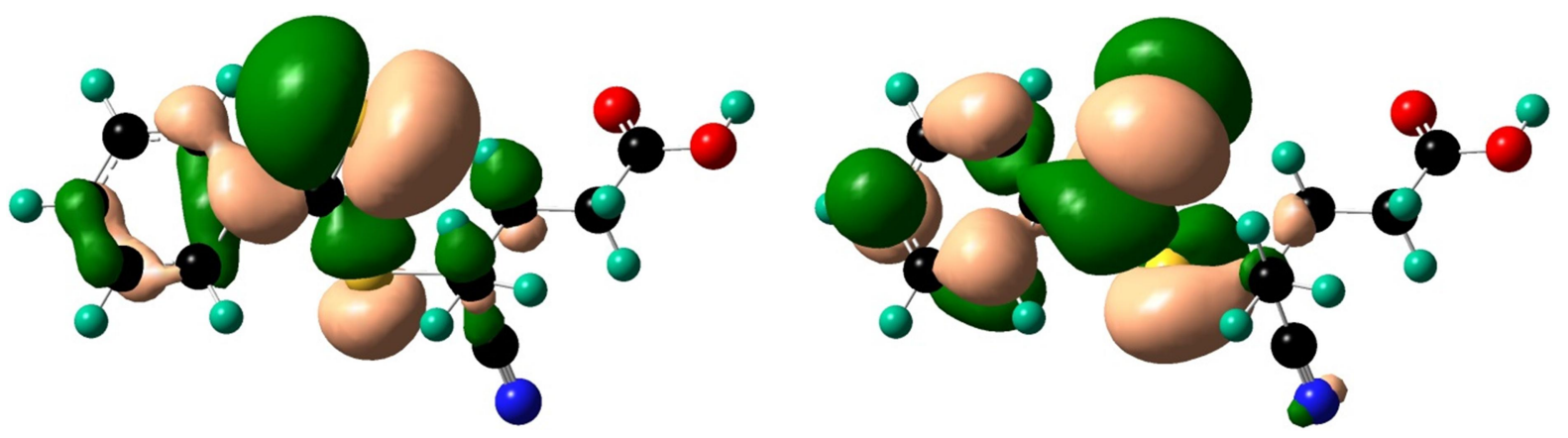


\section{WILEY-VCH}

CPD (RA $)$
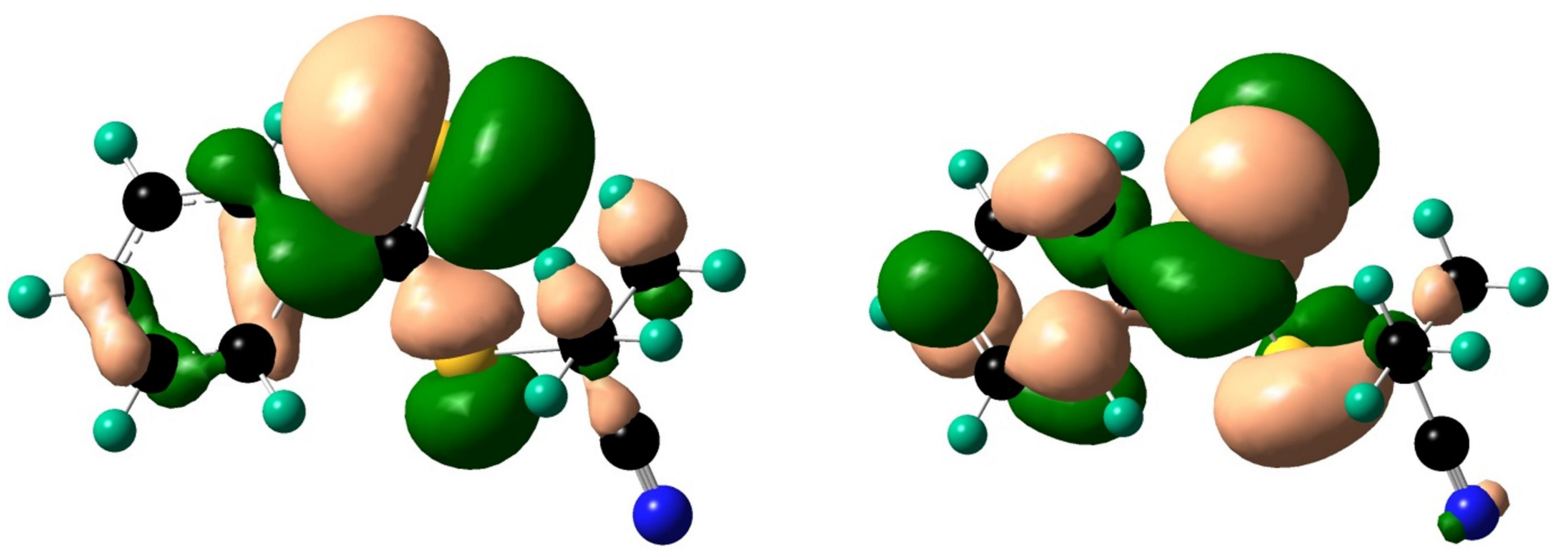

$\mathrm{CDB}\left(\mathrm{RA}_{3}\right)$
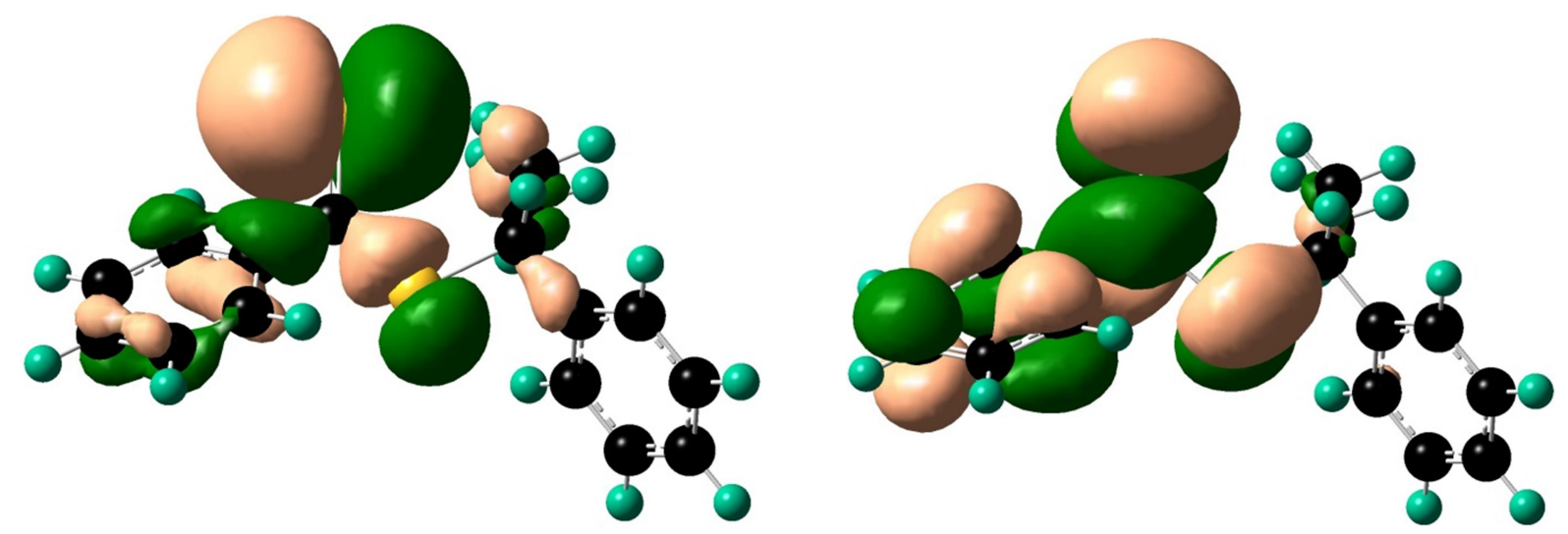

Xanthate (RA4)
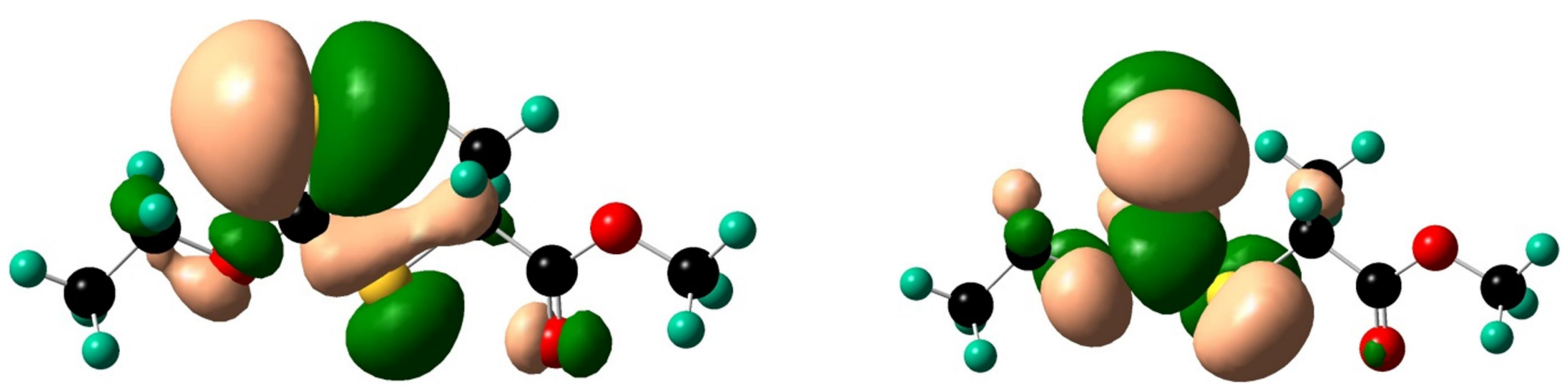


\section{WILEY-VCH}

1

2

3

4

5

6

7

8

9

10

11

12

13

14

15

16

17

18

19

20

21

22

23

24

25

26

27

28

29

30

31

32

33

34

35

36

37

38

39

40

41

42

43

44

45

46

47

48

49

50

51

52

53

54

55

56

57

58

59

60

61

62

63

64

65

$\operatorname{BSTP}\left(\mathbf{R A}_{5}\right)$
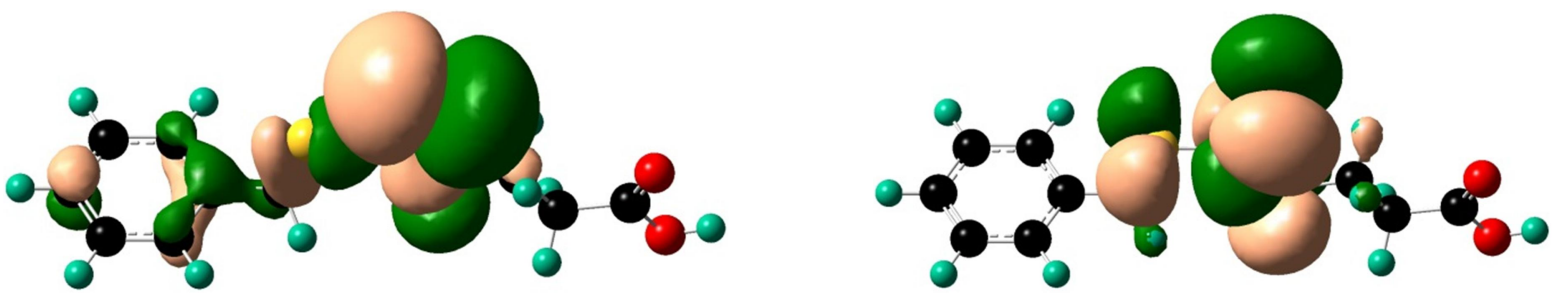

BTPA (RA $\mathbf{R A}_{6}$
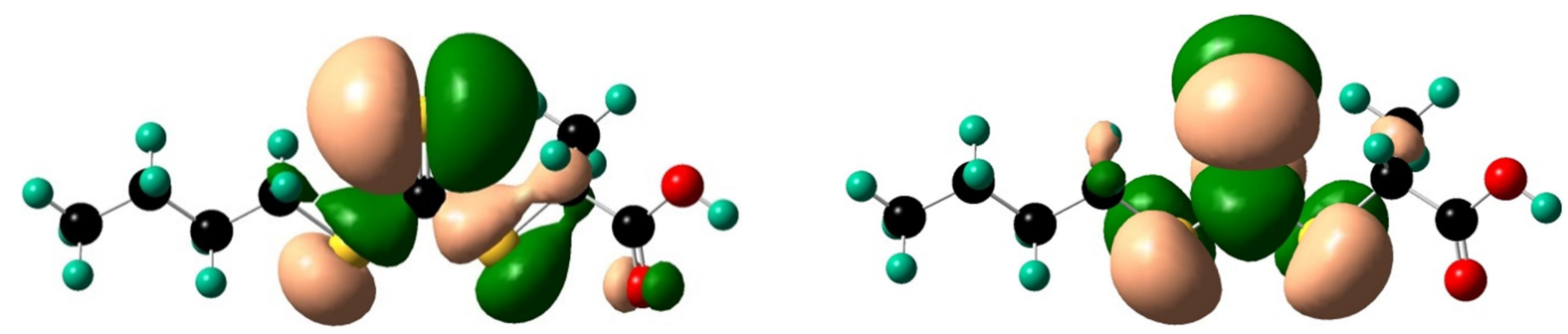

Figure S5. The molecular orbitals (HOMO and LUMO) of catalysts and the RAFT agents considered in the present work. 


\section{WILEY-VCH}

Table S3. Detailed TDDFT orbital energy analysis (in $\mathrm{eV}$ ) at M05/6-31G(d)+D3 level of theory for some of the complexes studied in the present work in the triplet state. The energy values highlighted in red are the orbitals where we have the major contributions from the RAFT agents.

\begin{tabular}{|c|c|c|c|c|c|c|c|c|}
\hline \multirow[t]{2}{*}{ \# } & \multicolumn{8}{|c|}{ PheoA $\left(\mathrm{PC}_{1}\right)$-RAFT } \\
\hline & Initiation Step & RAFT agents & HOMO & LUMO & LUMO + 1 & LUMO + 2 & Crucial Transition & Uphill(U) / Downhill(D) \\
\hline 1 & $\mathrm{PC}_{1}-\mathrm{RA}_{1}$ & CPADB & -3.905 & -2.093 & -1.768 & -0.756 & 0.325 & $\mathrm{D}$ \\
\hline 2 & $\mathrm{PC}_{1}-\mathrm{RA}_{2}$ & CPD & -3.981 & -2.527 & -1.899 & -0.842 & 1.453 & $\mathrm{D}$ \\
\hline 3 & $\mathrm{PC}_{1}-\mathrm{RA}_{3}$ & $\mathrm{CDB}$ & -3.826 & -1.854 & -1.795 & -0.890 & 0.964 & $\mathrm{D}$ \\
\hline
\end{tabular}




\section{WILEY-VCH}

Table S4. Detailed TDDFT orbital energy analysis (in eV) at M05/6-31G(d)+D3 level of theory for all the complexes studied in the present work with the DMSO as the implicit solvent. The energy values highlighted in red are the orbitals where we have the major contributions from the RAFT agents.

\begin{tabular}{|c|c|c|c|c|c|c|c|c|}
\hline \multirow[t]{2}{*}{ \# } & \multicolumn{8}{|c|}{ PheoA(PC $\left.{ }_{1}\right)$-RAFT } \\
\hline & Initiation Step & RAFT agents & HOMO & LUMO & $\mathrm{LUMO}+1$ & LUMO + 2 & Crucial Transition & Uphill(U) / Downhill(D) \\
\hline 1 & $\mathrm{PC}_{1}-\mathrm{RA}_{1}$ & CPADB & -5.322 & -2.652 & -2.368 & -1.816 & 0.284 & $\mathrm{U}$ \\
\hline 2 & $\mathrm{PC}_{1}-\mathrm{RA}_{2}$ & CPD & -5.158 & -3.117 & -2.463 & -1.766 & 0.654 & $\mathrm{D}$ \\
\hline 3 & $\mathrm{PC}_{1}-\mathrm{RA}_{3}$ & $\mathrm{CDB}$ & -5.380 & -2.712 & -2.228 & -1.826 & 0.484 & $\mathrm{U}$ \\
\hline 4 & $\mathrm{PC}_{1}-\mathrm{RA}_{4}$ & Xanthate & -5.372 & -2.712 & -1.868 & -1.145 & 1.567 & $\mathrm{U}$ \\
\hline 5 & $\mathrm{PC}_{1}-\mathrm{RA}_{5}$ & BSTP & -5.311 & -2.670 & -1.812 & -1.648 & 1.022 & $\mathrm{U}$ \\
\hline 6 & $\mathrm{PC}_{1}-\mathrm{RA}_{6}{ }^{\mathrm{a})}$ & ВTPA & -5.353 & -2.689 & -1.900 & -1.808 & 2.510 & $\mathrm{U}$ \\
\hline
\end{tabular}

${ }^{\mathrm{a})} \mathrm{LUMO}+4:-0.179 \mathrm{eV}$, which makes the Crucial Transition to be $2.510 \mathrm{eV}$. 


\section{WILEY-VCH}

\section{Experimental section:}

Materials: Methyl methacrylate (MMA, 99\%), 2-Cyano-2-propyl benzodithioate (CPD), and pheophorbide a (PheoA) were all purchased from Sigma-Aldrich. Deinhibition of monomers was performed by percolating over a column of basic alumina (Ajax Chemical, AR). Azobisisobutyronitrile (AIBN) was purified by recrystallization in methanol. Dimethyl sulfoxide (DMSO, Ajax Chemical), diethyl ether (Ajax Chemical), methonal (Merck) and petroleum spirit (Ajax Chemical) were used as received.

Gel permeation chromatography (GPC) was performed using dimethylacetamide (DMAc) as the eluent. The GPC system was a Shimadzu modular system comprising an auto injector, a Phenomenex $5.0 \mu \mathrm{m}$ beadsize guard column $(50 \times 7.5 \mathrm{~mm})$ followed by four Phenomenex 5.0 $\mu \mathrm{m}$ bead-size columns $\left(10^{5}, 10^{4}, 10^{3}\right.$ and $\left.10^{2} \AA\right)$ for DMAc system, two MIX C columns provided by Polymer Lab for THF system, and a differential refractive-index detector and a UV detector. The system was calibrated with narrow molecular weight distribution polystyrene standards with molecular weights of 200 to $10^{6} \mathrm{~g} \mathrm{~mol}^{-1}$.

Photopolymerization reactions were carried out in the reaction vessel where the reaction mixtures are irradiated by RS Component PACK LAMP RGB blue/green/red LED lights (5 $\mathrm{W}, \lambda_{\max }=530 \mathrm{~nm}$ (green) and $635 \mathrm{~nm}$ (red)) showed below. The distance of the samples to light bulb was $6 \mathrm{~cm}$. The RGB multi-colored LED light bulb with remote control was purchased from RS Components Australia.
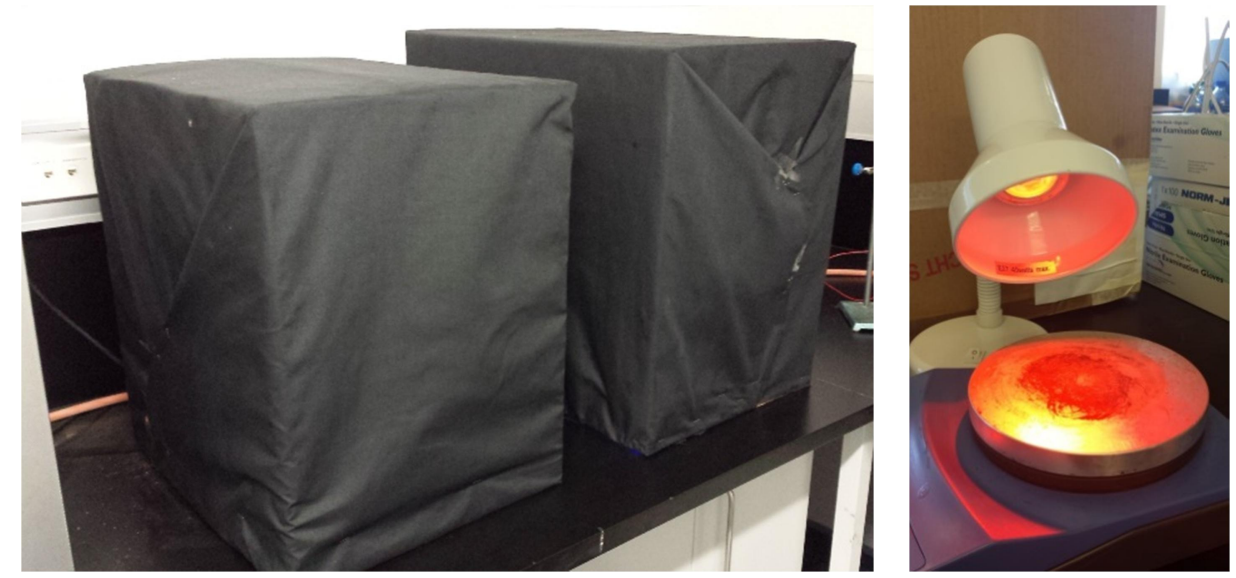

Synthesis of macro-RAFT agent of CPD-MMA $\mathrm{A}_{m}$ using thermal initiation.

[MMA]:[CPD]:[AIBN] =200:1:0.1. A reaction stock solution consisting of DMSO $(0.5 \mathrm{~mL})$, MMA (0.47 g, $4.7 \mathrm{mmol}), \mathrm{CPD}(5.2 \mathrm{mg}, 0.0235 \mathrm{mmol})$, and AIBN $\left(0.39 \mathrm{mg}, 2.36 \times 10^{-3}\right.$ mmol) was prepared in a $4 \mathrm{~mL}$ glass vial. The glass vial was sealed with a rubber septum and the stock solution was degassed with nitrogen for 20 minutes. The reaction mixture was then immersed in oil bath at $70^{\circ} \mathrm{C}$. After $6 \mathrm{~h}$, aliquots of the reaction mixtures were withdrawn and analyzed by GPC to measure number-average molecular weights $\left(M_{\mathrm{n},}, \mathrm{GPC}\right)$ and polydispersities $\left(M_{\mathrm{w}} / M_{\mathrm{n}}\right),{ }^{1} \mathrm{H}$ NMR to measure monomer conversion. Conversion $=65 \%, M_{\mathrm{n}}$, GPC $=12990 \mathrm{~g} / \mathrm{mol}, M_{\mathrm{w}} / M_{\mathrm{n}}=1.10$. The final solution was purified via precipitation in methanol/petroleum ether $(1 / 1, \mathrm{v} / \mathrm{v})$. The precipitated pink product was collected for further chain extension.

\section{Chain extension of CPD-MMAm using PET-RAFT polymerization.}




\section{WILEY-VCH}

[MMA]:[CPD-PMMA $\mathrm{m}]:[\mathrm{PheoA}]=1000: 1: 0.005(5 \mathrm{ppm})$. A reaction stock solution consisting of DMSO (1 mL), MMA (0.47 g, $4.7 \mathrm{mmol})$, CPD-MMA $(60 \mathrm{mg}, 0.0046 \mathrm{mmol}$, $\left.M_{\mathrm{n}}=12990 \mathrm{~g} / \mathrm{mol}, M_{\mathrm{w}} / M_{\mathrm{n}}=1.10\right)$ and PheoA $\left(0.014 \mathrm{mg}, 2.3 \times 10^{-5} \mathrm{mmol}, 5 \mathrm{ppm}\right.$ relative to monomer) was prepared in a $4 \mathrm{~mL}$ glass vial. The glass vial was sealed with a rubber septum and the stock solution was degassed with nitrogen for 20 minutes. The reaction mixture was then irradiated under red LED light $\left(\lambda_{\max }=635 \mathrm{~nm}\right)$ at room temperature. After $12 \mathrm{~h}$ irradiation, aliquots of the reaction mixtures were withdrawn and analyzed by GPC to measure number-average molecular weights $\left(M_{\mathrm{n}, \mathrm{GPC}}\right)$ and polydispersities $\left(M_{\mathrm{w}} / M_{\mathrm{n}}\right) \cdot M_{\mathrm{n}, \mathrm{GPC}}=$ $52040 \mathrm{~g} / \mathrm{mol}, M_{\mathrm{w}} / M_{\mathrm{n}}=1.23$. 